\title{
Electrical resistivity tomography and time-domain induced polarization field investigations of geothermal areas at Krafla, Iceland: comparison to borehole and laboratory frequency-domain electrical observations
}

\author{
L. Lévy ${ }^{\oplus},{ }^{1,2}$ P.K. Maurya ${ }^{\oplus}, 3$ S. Byrdina, ${ }^{4}$ J. Vandemeulebrouck, ${ }^{4}$ F. Sigmundsson, ${ }^{2}$ \\ K. Árnason, ${ }^{5}$ T. Ricci, ${ }^{6}$ D. Deldicque,${ }^{1}$ M. Roger, ${ }^{1}$ B. Gibert ${ }^{7}$ and P. Labazuy ${ }^{8}$ \\ ${ }^{1}$ Laboratoire de Géologie, Ecole Normale Supérieure - PSL, CNRS, UMR 8538, Paris 75005, France. E-mail: lea.levy@ens.fr \\ ${ }^{2}$ Nordic Volcanological Center, Institute of Earth Sciences, University of Iceland, 101 Reykjavik, Iceland \\ ${ }^{3}$ Institute of Geoscience, HydroGeophysics Group, Aarhus University, 8000 Aarhus, Denmark \\ ${ }^{4}$ Université Grenoble Alpes, Université Savoie Mont Blanc, CNRS, IRD, IFSTTAR, ISTerre, 38000 Grenoble, France \\ 5 ÍSOR - Iceland GeoSurvey, 108 Reykjavik, Iceland \\ ${ }^{6}$ Istituto Nazionale di Geofisica e Vulcanologia, Sezione Romal, via di Vigna Murata 605, 00143 Roma, Italy \\ ${ }^{7}$ Géosciences Montpellier, Université de Montpellier, Université des Antilles, CNRS, 34090 Montpellier, France \\ ${ }^{8}$ Université Clermont Auvergne, CNRS, IRD, OPGC, Laboratoire Magmas et Volcans, F-63000 Clermont-Ferrand, France
}

\section{SUMMAR Y}

Interaction of $\mathrm{H}_{2} \mathrm{~S}$ and basaltic rocks in volcanic geothermal areas can originate from natural up-flow of magmatic fluids or $\mathrm{H}_{2} \mathrm{~S}$ artificial re-injection in relation to geothermal exploitation, both causing pyrite mineralization. We study the possibility to track these processes with electrical impedance field measurements. Electrical Resistivity Tomography (ERT) and TimeDomain Induced Polarization (TDIP) measurements were performed along thirteen $1.24 \mathrm{~km}$ long profiles, at three different sites around the eastern caldera rim of the Krafla caldera: (i) a 'cold altered' site affected by past hydrothermal circulations, (ii) a hot active site and (iii) a 'cold un-altered' site, unaffected by hydrothermal circulations. We present 2-D inversions of direct current (DC) resistivity, maximum phase angle of the electrical impedance (MPA) and relaxation time. The maximum depth of investigation for the MPA is $200 \mathrm{~m}$, obtained in zones of high resistivity, corresponding to fresh and recent unaltered basalt. At the hot and cold altered sites, the field resistivities are compared to in situ borehole logs and laboratory complex resistivity measurements on rock samples from the boreholes. The laboratory complex resistivity was measured at six different pore water conductivities, ranging from 0.02 to 5 $\mathrm{S} \mathrm{m}^{-1}$, and frequency in the range $10^{-2}-10^{6} \mathrm{~Hz}$. The time-range investigated in our field TDIP measurements was approximately $0.01-8 \mathrm{~s}$.

At the cold altered site, the inverted resistivity is consistent with both borehole observations and laboratory measurements. At the hot site, resistivity from field inversion and borehole $\operatorname{logs}$ are consistent. Comparing inversion results and borehole logs to laboratory resistivity measured on core samples at room temperature reveals that a correction coefficient for the effect of temperature on resistivity of 6 per cent per ${ }^{\circ} \mathrm{C}$ is appropriate at investigated depths. This exceptionally high temperature correction coefficient suggests a dominant influence of interface and interfoliar conduction, characteristic of smectite-rich rocks, compared to electrolyte conduction. High MPA is attributed to the presence of pyrite at the hot site and of iron-oxides at the cold unaltered site, through joint consideration of MPA together with DC resistivity and relaxation time. TDIP measurements offer the possibility to detect the presence of metallic minerals at shallow depth and distinguish between pyrite and iron-oxides. The abundance of highly conductive smectite in altered volcanic rocks represents a challenge for resolving IP parameters, because the low resistivity created by abundant smectite limits the data quality of the measured voltage discharge. 
Key words: Hydrogeophysics; Hydrothermal Systems; Electrical Resistivity Tomography.

\section{INTRODUCTION}

Iron-sulphides (e.g. pyrite) and expandable clays (e.g. smectite) are common secondary minerals in magmatic-hydrothermal systems (Meunier 2005). Their abundant presence is an indication of sustained hydrothermal activity (Beaufort et al. 1995; Patrier et al. 1996; Gudmundsson et al. 2010; Libbey \& Williams-Jones 2013). Therefore, mapping underground smectite and pyrite distribution can constrain the location of hydrothermal circulations. Electrical Resistivity Tomography (ERT) is a method of subsurface investigation, which maps the electrical resistivity of the rock matrix filled with pore fluids. The measured conductivity (and its inverse, resistivity) is particularly sensitive to the salinity and temperature of the fluids, and also to the presence of minerals with significant surface or interfoliar conduction, such as smectite (Waxman \& Smits 1968; Flóvenz et al. 2005; Lévy et al. 2018). Induced Polarization (IP) is a complementary method, which investigates the electrical charge storage capability of the rock matrix, in addition to the electrical conductivity. IP is particularly sensitive to the presence of sulphides and iron-oxides (Pelton et al. 1978; Gurin et al. 2015) and also to the presence of conductive fluid and clay minerals (Lesmes \& Frye 2001; Weller et al. 2013; Gurin et al. 2015). Several studies also suggest that clay minerals, including smectite, have an important IP signal and could be mapped using IP methods (Slater \& Sandberg 2000; Leroy et al. 2017; Revil et al. 2017a,b). However, according to Parkhomenko (1971) and Vinegar \& Waxman (1984), the largest IP effects are observed for clay contents in the range 3-10 per cent. Moreover, the recent study by Lévy et al. (2019) on volcanic rocks shows that the polarization associated to altered volcanic rocks decreases when the smectite volume increases, for a given volume of metallic particles. Indeed, electrical conduction occurring through connected smectite particles would prevent polarization to occur (Lévy et al. 2018).

IP can be either measured in frequency-domain (FDIP) or in time-domain (TDIP). In both cases, it is possible to obtain the average relaxation time, in addition to the amplitude of the polarization, usually represented by the chargeability or the phase angle (Flores Orozco et al. 2012; Kemna et al. 2012; Fiandaca et al. 2018; Flores Orozco et al. 2018; Maurya et al. 2018). The relaxation time is the time taken by the charge carriers (ions, electrons or holes, responsible for polarization) to relax, that is to return to their initial position (Revil et al. 2015; Misra et al. 2016; Abdulsamad et al. 2017; Bücker et al. 2018).

Volcanic rocks can contain iron-oxides, sulphides and clay minerals. Iron-oxides, formed during primary magmatic crystallization, are mostly present in fresh unaltered basalts, whereas pyrite, smectite (and clay minerals in general) are secondary minerals, more abundant in altered volcanic rocks. Laboratory frequencydomain electrical measurements on core samples from the Krafla volcano (Iceland) show that pyrite can be distinguished from ironoxides in volcanic environments, because pyrite is associated to low-resistivity (smectite-rich) rocks, whereas iron-oxides are associated to high-resistivity (crystalline and dense) rocks (Lévy et al. 2019). Moreover, pyrite crystals formed by hydrothermal alteration tend to be larger and more connected than iron-oxides, which are usually small and homogeneously disseminated in volcanic rocks. The presence of larger or connected metallic particles leads to longer relaxation times than small and disseminated metallic particles so that relaxation time is another possible discrimination parameter between pyrite and iron-oxides (Pelton et al. 1978; Gurin et al. 2015; Hupfer et al. 2016; Gurin et al. 2018). Here, we investigate to what extent results obtained with frequency-domain IP measurements can be used, in practice, to interpret time-domain IP (TDIP) field measurements in volcanic environments.

The Krafla area is well suited for this type of investigation since it is the site of a significant geothermal production and smectites, sulphides and iron oxides can be observed at variable concentrations in the geological formations of the geothermal reservoir. The Krafla volcano is composed of a $15 \mathrm{~km}$ diameter central volcano and a $100 \mathrm{~km}$ long (and 4 to $19 \mathrm{~km}$ wide) NNE-SSW trending fissure swarm running through it (Ármannsson et al. 1987; Hjartardóttir et al. 2012, 2016). Caldera rims, shown in Fig. 1, have been defined by mapping a reddish welded ash flow, of dacitic composition, whose formation is related to the first collapse of the caldera during the early part of the last interglacial period, about $100000 \mathrm{yr}$ ago (Sæmundsson 1991; Jónasson 1994; Sæmundsson 2015). About $24000 \mathrm{yr}$ ago, a rhyolitic fissure eruption beneath thin ice inside the caldera formed Hrafntinnuhryggur (Fig. 1), a $2.5 \mathrm{~km}$ long NNESSW trending ridge of obsidian (Sæmundsson et al. 2000; Tuffen \& Castro 2009). Except for isolated episodes of rhyolitic volcanism, most of volcanic deposits at Krafla originate from tholeiitic basaltic magmas, with a mineral composition dominated by olivine, clinopyroxene, plagioclase and minor iron-titanium oxides (e.g. Sigmarsson \& Steinthórsson 2007). In general, the geology and tectonics at the Krafla caldera have been extensively studied (Sigmundsson 2006) and allow putting into context the inversion results from near-surface geophysics investigations. Finally, numerous Transient Electromagnetic (TEM) and Magnetotelluric (MT) campaigns have been carried out at Krafla (Árnason et al. 2007; Gasperikova et al. 2011).

The aim of this study is to determine the usefulness of combining ERT and TDIP measurements in volcanic environments for geothermal exploration. The comparative analysis conducted here is based, in an original way, on ERT and TDIP field measurements around three boreholes, as well as in situ borehole resistivity observations and laboratory frequency-domain IP measurements on borehole samples. In addition, knowledge of the lithology and mineral composition at the investigated sites, thanks to borehole samples, allows validating the interpretations.

\section{MATERIALS AND METHODS}

\subsection{Study sites}

The Krafla high-temperature geothermal field has about 40 production boreholes. Several exploration boreholes (including KH1, KS1 and KH3) have also been drilled. Our study focuses on three sites, centred around the KS1, KH1 and $\mathrm{KH} 3$ boreholes, which are all on the eastern side of the Krafla caldera. We named the sites according to these boreholes (Fig. 1). A total of thirteen 1.2-kmlong profiles were measured with ERT and TDIP: four profiles at KS1 (ISL-1 to ISL-4), all of them parallel with $100 \mathrm{~m}$ spacing inbetween; four profiles at KH1, three of them parallel with $100 \mathrm{~m}$ spacing in-between and one of them perpendicular to the others (ISL-10 to ISL-13); five profiles at KH3, all of them parallel with $50 \mathrm{~m}$ spacing in-between (ISL-5 to ISL-9). An additional long ERT 

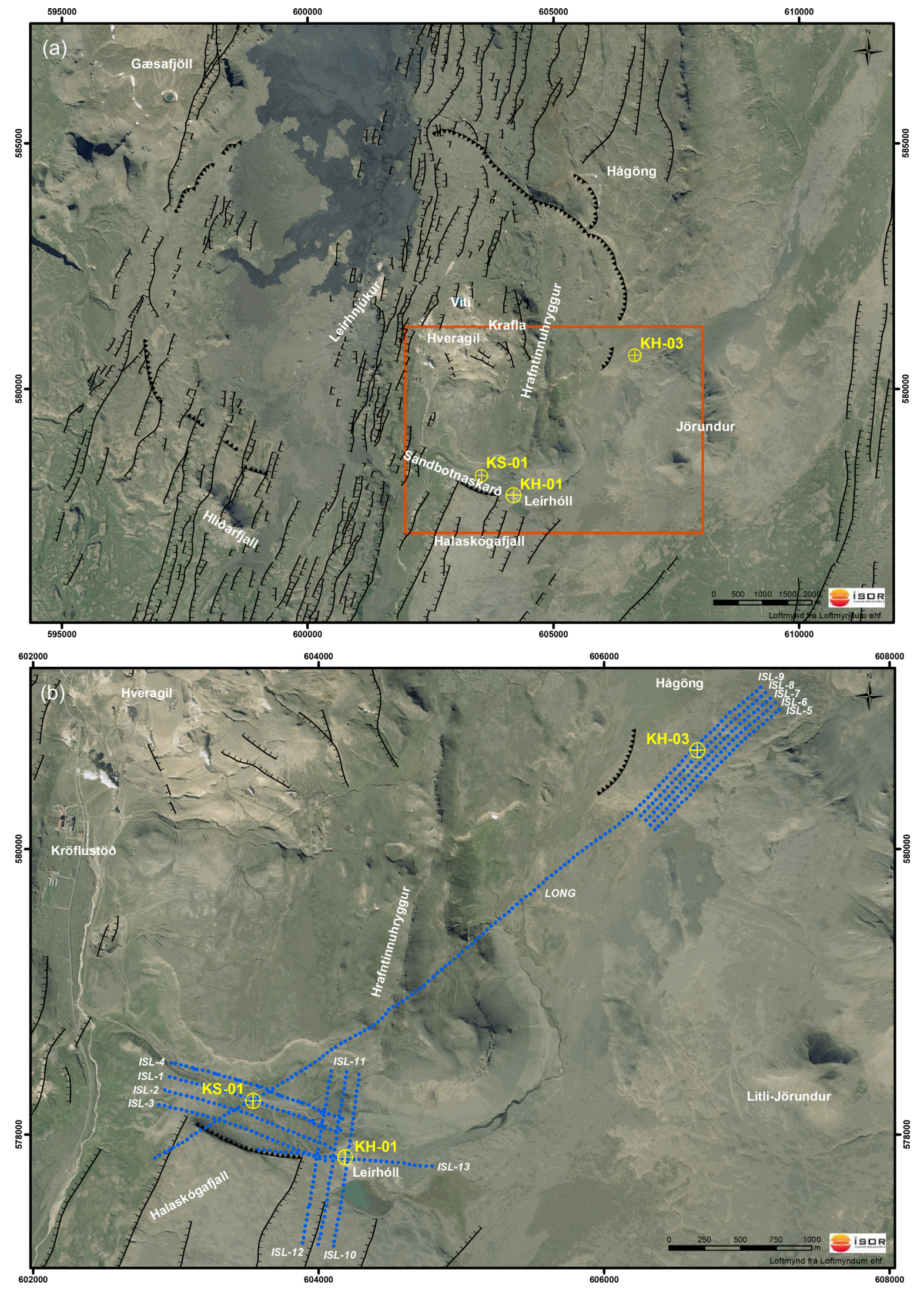

Figure 1. Krafla caldera: (a) aerial map of the Krafla central volcano, with known caldera rims and faults represented as black lines (Saemundsson et al. 2012) and boreholes used in this study as yellow circles with crosses; (b) zoom on the eastern part, where the geoelectric soundings were performed. The blue markers indicate the position of electrodes along the profiles. The geothermal power plant operated by Landsvirkjun is marked by the white name Kröflustöð. 
profile (LONG) was measured in the continuation of ISL-9 profile all the way to KS1 site. Boreholes KH1 and KH3 were cored down to 200 and $400 \mathrm{~m}$, respectively, while borehole KS1 was drilled down to $2.5 \mathrm{~km}$ and drill-cuttings were retrieved. Steel casings are present in boreholes KS1, KH3 and KH1, down to 900, 30 and $12 \mathrm{~m}$, respectively.

\subsection{Laboratory observations}

A total of 25 and 13 core samples from boreholes KH1 and KH3, respectively, were available for comparison to field measurements (Table A1 in Appendix). Amongst the 25 samples from KH1 used in this study, F58 and F61 were analysed by Flóvenz et al. (2005) and Kristinsdóttir et al. (2010). The rest of the samples were analysed by Lévy et al. (2018) and Lévy et al. (2019), who provide estimates of the overall mineral distribution, influence of clay minerals on in-phase electrical conductivity at $1 \mathrm{kHz}$ and influence of sulphides and iron-oxides on the phase-angle spectra and real part of the impedance. The host rock of the cores varies from volcanic glass (sub-glacial eruptions) to crystalline basalt (centre of lava layers or dykes).

Borehole KH1 shows alternating layers of very altered volcanic glass, altered basaltic breccia and dense crystallized layers. The rock is overall very fractured and evidence of boiling (e.g. platy calcite, amorphous silica) is found in fractures. The dominant mineralogy is composed of secondary minerals: smectite, zeolites, quartz, calcite and pyrite. Primary minerals, such as plagioclases, pyroxenes and iron-oxides are sometimes observed in crystalline samples with little alteration (centre of lava flows or dykes, less exposed to fluid flow).

Borehole KH3 has an uppermost dense layer (31-58 m), composed of fresh and crystalline basaltic lava, which mostly contains pyroxenes, plagioclases and iron-oxides (formed during magmatic crystallization), followed by a very altered layer (58-96 m) of former volcanic glass, named hyaloclastite. This second layer contains up to $50 \mathrm{wt}$. per cent of smectite. Below this layer, basaltic breccia and lava flows are observed, mostly unaltered below $150 \mathrm{~m}$. In general, little fracturation is observed.

No cores were available in borehole KS1 but geological observations of drill-cuttings indicate that the first $350 \mathrm{~m}$ are mostly composed of fresh volcanic glass and fresh basaltic lava containing abundant iron-oxides. No evidence of hydrothermal alteration is found above $350 \mathrm{~m}$ (Gudmundsson et al. 2007).

The frequency-domain electrical impedance of the core samples was measured in the laboratory with a Solartron 1260 impedancemeter and a 4-electrode set-up, where the voltage (non-polarizable $\mathrm{Ag} / \mathrm{AgCl}$ ) and current (nickel) electrodes are separated. The quality of the impedance-meter calibration is illustrated in Supporting Information Fig. S1 with a comparison between measurements and predictions for three networks of ideal resistors and capacitors of known impedance. The uncertainty of the phase-angle measurement is estimated to be $1 \mathrm{mrad}$ below $1 \mathrm{kHz}$, based on measurements made on a cylindrical tube filled with water at different salinities (Supporting Information Fig. S2). More details on the saturation procedure and electrical measurements can be found in Lévy et al. (2018) and Lévy et al. (2019).

\subsection{In situ borehole observations}

In situ temperature logs were obtained shortly after drilling, in 1991, 2003 and 2007 for KH1, KH3 and KS1, respectively. We consider that the temperatures are similar at the time of our experiments. In borehole $\mathrm{KS} 1$, a temperature below $4{ }^{\circ} \mathrm{C}$ is observed in the first $300 \mathrm{~m}$ but reaches $300{ }^{\circ} \mathrm{C}$ at $2500 \mathrm{~m}$ depth (Fig. 2). In $\mathrm{KH} 3$, the temperature is about $10^{\circ} \mathrm{C}$ in the first $250 \mathrm{~m}$. On the other hand, a strong temperature gradient is observed in $\mathrm{KH} 1$, with the temperature reaching $175^{\circ} \mathrm{C}$ at $200 \mathrm{~m}$ depth.

Electrical logs were measured with a $16 / 64$ probing tool along the entire depth-range in KH1 $(200 \mathrm{~m})$ but only above $140 \mathrm{~m}$ in KH3 and only below $300 \mathrm{~m}$ in KS1 (Gudmundsson 1991; Jónsson et al. 2003; Gudmundsson et al. 2007). The 16/64 probing tool measures the electrical resistivity every $50 \mathrm{~cm}$. It uses the so-called normal electrode configuration, where the current electrode B is connected to the ground at the surface and current electrode A is at the bottom of the probe. Potential electrodes $\mathrm{M}$ and $\mathrm{N}$ are both in the borehole and the fixed distance of $22 \mathrm{~m}$ between $\mathrm{M}$ and $\mathrm{N}$ is considered to be infinite. The electrode spacing is defined as the distance between A (current) and M (potential) and can be either 16 inches or 64 inches (Helander 1983). The 16-inch measurement is more sensitive to local heterogeneity than the 64-inch measurement. The names 'shallow' and 'deep', commonly used for 16-inch and 64-inch, respectively, refer to the horizontal distance of penetration into the rock matrix. The true resistivity, corrected for the resistivity of the water inside the borehole, is not considered in our case so that there is a possible constant shift in the resistivity values obtained from logging. Neutron-Neutron (NN) logs were measured along the whole depth-range in KH1 and $\mathrm{KH} 3$ but only below $300 \mathrm{~m}$ in $\mathrm{KS} 1$. The NN logging tool used here is composed of a neutron-source (radioactive Americium-Beryllium) and a neutron-receiver, which measures the number of counts (number of neutrons arriving) per second (cps) (Scott 1984).

\subsection{Field measurements}

\subsubsection{Background on ERT and TDIP}

ERT consists of injecting a Direct Current (DC) along a profile through grounded electrodes (A and $\mathrm{B}$ ) and measuring the resulting voltage at two other electrodes ( $M$ and $N$ ), as presented in Fig. 3. The quadrupole A-B-M-N is selected at each step of the acquisition protocol from the electrodes available on the profile. For each quadrupole, the apparent resistivity $\rho_{\mathrm{a}}$ is calculated by eq. (1).

$\rho_{\mathrm{a}}=k \frac{V_{\mathrm{M}}-V_{\mathrm{N}}}{I_{\mathrm{AB}}}$,

where $I_{\mathrm{AB}}$ is the current injected between electrodes $\mathrm{AB}, V_{\mathrm{M}}$ and $V_{\mathrm{N}}$ the potentials measured at electrodes $\mathrm{M}$ and $\mathrm{N}$, respectively, and $k$ the so-called geometrical factor, defined in eq. (2) (e.g. Bertin \& Loeb 1976).

$k=\frac{2 \pi}{\frac{1}{\mathrm{AM}}-\frac{1}{\mathrm{AN}}-\frac{1}{\mathrm{BM}}+\frac{1}{\mathrm{BN}}}$.

Each apparent resistivity measurement averages the true resistivity of the Earth down to the penetration depth of the electrical current, which depends on the intensity of the current injected, the electrode configuration, but also the conductivity of the medium and the period of the electrical signal in case of a sinuisoidal current (e.g. Telford et al. 1990). A convenient means to display results of ERT measurements at a profile is a 2-D 'pseudo-section' plot, which is obtained by placing each apparent resistivity measurement at a horizontal midpoint and a pseudo-depth (Loke \& Barker 1996). The pseudo-depth is defined as the median 'effective' depth of investigation of the array and is calculated based on the Frechet derivatives 


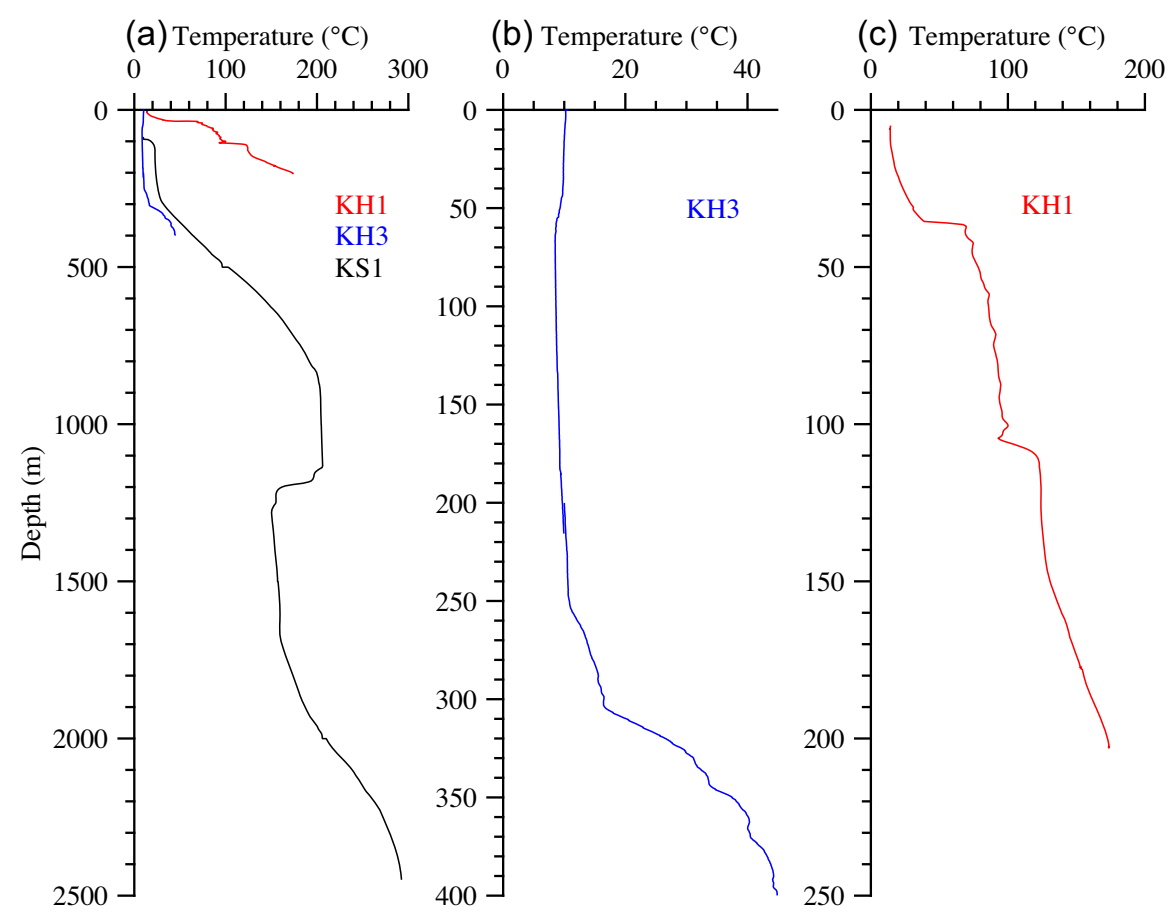

Figure 2. Temperature profiles in (a) boreholes KH1, KH3 and KS1, (b) borehole KH3 and (c) borehole KH1. Note the different scales in depth and temperature in the three figures. The temperature profiles of KH1 (hot) and KH3 (cold) are shown in red and blue, respectively.

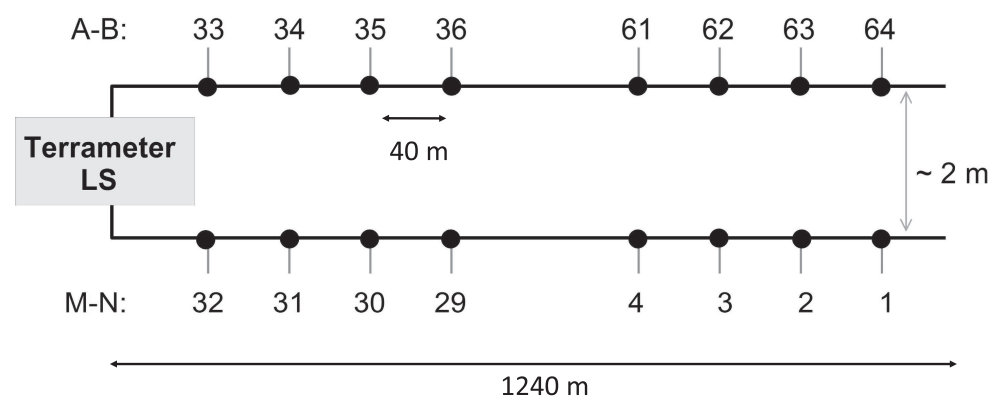

Figure 3. Multicable setup for ERT-TDIP measurements with cable separation to reduce the capacitive coupling. The electrodes 1-32 are used as potential electrodes (M-N), while electrodes 33-64 are used as injection electrodes (A-B). Some sets of measurements were recorded with the reciprocal configuration: 1-32 for current and 33-64 for voltage, in order to verify the symmetry of the measurement. As an example, the ABMN electrode numbers of the first measurement for a Wenner configuration are: 646123.

for a homogeneous half space (Edwards 1977; Loke 2004; Menke 2012).

Time-Domain Induced Polarization (TDIP) consists of analysing the time-dependent voltage signal, recorded with an appropriate sampling rate (e.g. $1000 \mathrm{~Hz}$ or more). Upon injection of a squarewave current, a voltage progressively builds up when the current is on, during the 'charge' $T_{\text {on }}$, and progressively decreases to zero when the current is turned off, during the 'discharge' $T_{\text {off. }}$ The integral apparent chargeability $<\mathrm{M}>$ in $\mathrm{msec}$, in a given time-window, is calculated with eq. (3) (e.g. Bertin \& Loeb 1976; Sumner 1976). $<\mathrm{M}>$ represents the area enclosed by the voltage discharge curve and its zero asymptote during this time-window, divided by the primary voltage $V_{\mathrm{p}}$.

$<M>=\int_{t_{1}}^{t_{2}} \frac{V(t)}{V_{\mathrm{p}}} \mathrm{d} t$,

where $t_{1}$ and $t_{2}$ delimit the integration window and $m_{0}=\frac{V(t)}{V_{\mathrm{p}}}$ $(\mathrm{mV} / \mathrm{V})$ is the apparent chargeability at a time $t$.
Smaller integral apparent chargeability is observed when smaller injection time is used, due to the finite length of the current pulse and in particular the fact that the voltage at the end of $T_{\text {on }}$ is not yet maximum (Fiandaca et al. 2012; Olsson et al. 2015). An example of this effect is illustrated with our field data in Supporting Information Fig. S3. Therefore, the exact waveform of the transmitted current needs to be taken into account in the inversion, including in particular $T_{\text {on }}$ and the number of pulses (Bertin \& Loeb 1976).

Capacitive and inductive coupling are common sources of noise in TDIP. Capacitive coupling can be reduced by using two distinct cables for current injection and potential measurement (Dahlin \& Leroux 2012). Inductive coupling is particularly important in nested arrays (electrodes $\mathrm{M}$ and $\mathrm{N}$ are between $\mathrm{A}$ and $\mathrm{B}$ ) and increases with the distance between electrodes and the conductivity of the ground, but mostly takes place in the early times after current turn-off (Ingeman-Nielsen \& Baumgartner 2006; Dahlin \& Leroux 2012). 
The spectral IP signal can be obtained from both frequencydomain (FDIP) and time-domain measurements (TDIP) in the field (e.g. Maurya et al. 2018).

\subsubsection{Data acquisition}

Two $1.24 \mathrm{~km}$ long parallel cables, with $50 \mathrm{~cm}$ long steel electrodes grounded every $40 \mathrm{~m}$, were connected to an ABEM Terrameter LS instrument: one cable for current injection and another for voltage measurement (Fig. 3). The setup, adapted from Dahlin \& Leroux (2012), avoids most of the capacitive coupling effects while working with a single instrument.

A square-wave current, ranging from 15 to $300 \mathrm{~mA}$, was injected by the ABEM Terrameter instrument through electrodes $\mathrm{A}$ and $\mathrm{B}$, using different current-on times $\left(T_{\mathrm{on}}\right)$, in the range $0.4-4 \mathrm{~s}$ and current-off times $\left(T_{\text {off }}\right)$, in the range $1-8 \mathrm{~s}$. The on-off pulse was repeated with reverse orientation (negative current) and the whole cycle was repeated (stacked) five times, in average. The voltage was measured at electrodes $\mathrm{M}$ and $\mathrm{N}$, both in the on-time for direct current (DC) resistivity measurement and in the off-time for voltage decay acquisition ( $1000 \mathrm{~Hz}$ sampling rate). The longest $T_{\text {on }}$ allowed by our Terrameter LS instrument was $4 \mathrm{~s}$ but $T_{\text {off }}$ could be up to $8 \mathrm{~s}$. Since we only recorded the voltage discharge during the offtime and wanted to be able to observe long decays - especially in cases where the ground was very chargeable - we used the longest possible $T_{\text {off }}$. As a consequence, our $T_{\text {on }}$ and $T_{\text {off }}$ were not equal and the acquisition cycle was not exactly a 50 per cent duty cycle.

Two types of electrode configurations were used for each profile: Wenner for its best signal-to-noise ratio and multigradient for its redundancy and efficiency when using a multichannel instrument (Dahlin \& Zhou 2006). The particular midpoint and pseudo-depth definitions for the multigradient array can be found in Dahlin \& Zhou (2006). Different injection times were used: $0.4,1.5$ and $4 \mathrm{~s}$ and reciprocal measurements were carried out with the $0.4 \mathrm{~s}$ injection time. The response of up to 264 quadrupoles was measured for each injection time on each profile, where one quadrupole corresponds to one position of electrodes A-B-M-N.

Water mixed with large amounts of dissolved sodium chloride, 'salty water', was added around the electrodes to lower the contact resistance between ground and electrodes. For profiles at KH1, bentonite was also used for the same reason. Contact resistances of electrodes were tested before each acquisition, using a current of $20 \mathrm{~mA}$, and were below $1 \mathrm{k} \Omega$ most of the time.

\subsubsection{Data processing and inversion}

Current is injected for a limited time only and does not follow an infinite step function, unlike assumed by theory (Olsson et al. 2015). For this reason, the waveform of the transmitted current needs to be taken into account in the inversion. The 2-D inversion code developed by Fiandaca et al. (2013) has integrated this option, as well as the possibility to model the full voltage decay in order to retrieve the spectral content of the IP signal from time-domain data sets, instead of only the integral chargeability. This code, incorporated in the software AarhusInv (Auken et al. 2014), was chosen for the inversions of TDIP data. Since the topography is considered in the inversions, the vertical axes of the 2-D profiles are displayed in terms of metres above sea level (m a.s.l) instead of depth.

The recorded full waveform data sets were re-processed using the signal processing scheme presented by Olsson et al. (2016).
Re-processing full waveform data includes: (i) integrating the DC resistivity during the last 10 or $100 \mathrm{~ms}$ of the on-time, instead of the entire on-time; (ii) gating the voltage decay in the off-time starting at $1 \mathrm{~ms}$, instead of $80 \mathrm{~ms}$; (iii) correcting for background drift related to spontaneous polarization and electrode polarization, using a drift model based on the time-domain expression of ColeCole model by Pelton et al. (1978), instead of a linear model and (iv) spikes removal at early recording times to increase the time window of usable IP signal. A high background drift was observed at late recording times (after $1 \mathrm{~s}$ ), probably due to a spontaneous potential generated by hydrothermal circulation. We considered the possibility of a background drift related to salty water flow but the volumes investigated (electrode spacing, $40 \mathrm{~m}$ here) were large compared to the volume where the salty water penetrated (few centimetres around the electrodes), so that this explanation seems unlikely.

The re-processed tasks were then filtered, using the software Aarhus Workbench, in order to remove outliers. For each quadrupole of each profile, apparent chargeability curves or part of the curves showing a non-decaying behaviour were filtered out manually. After manual processing, the time of the earliest usable signal varied from 10 to $100 \mathrm{~ms}$. No removal of electromagnetic coupling was performed, since the first milliseconds of the recorded signal were always unused.

At $\mathrm{KH} 3$, most of the discharge curves recorded were noisy, over the whole time-range and along the five profiles. A conductive near-horizontal body seems to be associated with particularly noisy voltage discharge curves, while clean IP decays are observed outside this body (Fig. 4). Below the conductive body, IP data were unusable. The remaining IP pseudo-sections after filtering the noisy voltage discharge curves, over the fives profiles at $\mathrm{KH} 3$, were considered not sufficient to resolve the IP parameters and only DC resistivity was inverted at this site.

For IP inversions at the other sites (KH1 and KS1), the following acquisitions settings were retrieved for each quadrupole and used to model the waveform of the transmitted current in the inversion: number of pulses, injected current, on-time, off-time, DC integration starting time, DC integration end time.

Inversion of TDIP data was performed using the re-parametrized 'maximum phase angle' (MPA) model suggested by Fiandaca et al. (2018) because less correlation exists between IP parameters in this model compared to the standard Cole-Cole model. The MPA is also a more straightforward parameter to obtain from laboratory measurements than the chargeability since no a priori model is required (see discussion in Lévy et al. 2019). The polarization phase angle is negative because the IP voltage lags the current. The phase angle represents polarization as a momentarily 'frozen' impedance vector (Sumner 1976). With MPA parametrization, the model space consists of DC resistivity, $\rho_{0}$, maximum phase angle, $\phi_{\max }$, relaxation time, $\tau_{\phi}$ (inverse of the angular frequency at which the phase angle reaches a maximum) and frequency exponent, $c$. The exponent $c$ was not used for interpretations. We also carried out inversions using the classical Resistivity Cole-Cole parametrization, in order to compute the normalized chargeability. We show inversion results using this parametrization for one profile at KH1 site in Supporting Information Fig. S4.

The depth of investigation (DOI) computation in AarhusInv is based on approximate covariance analysis, following Fiandaca et al. (2015). The analysis takes the noise in the data and the final derived model into account. In the results sections, DOI is shown as conservative (shallow) and less conservative (deeper). For each inversion, 

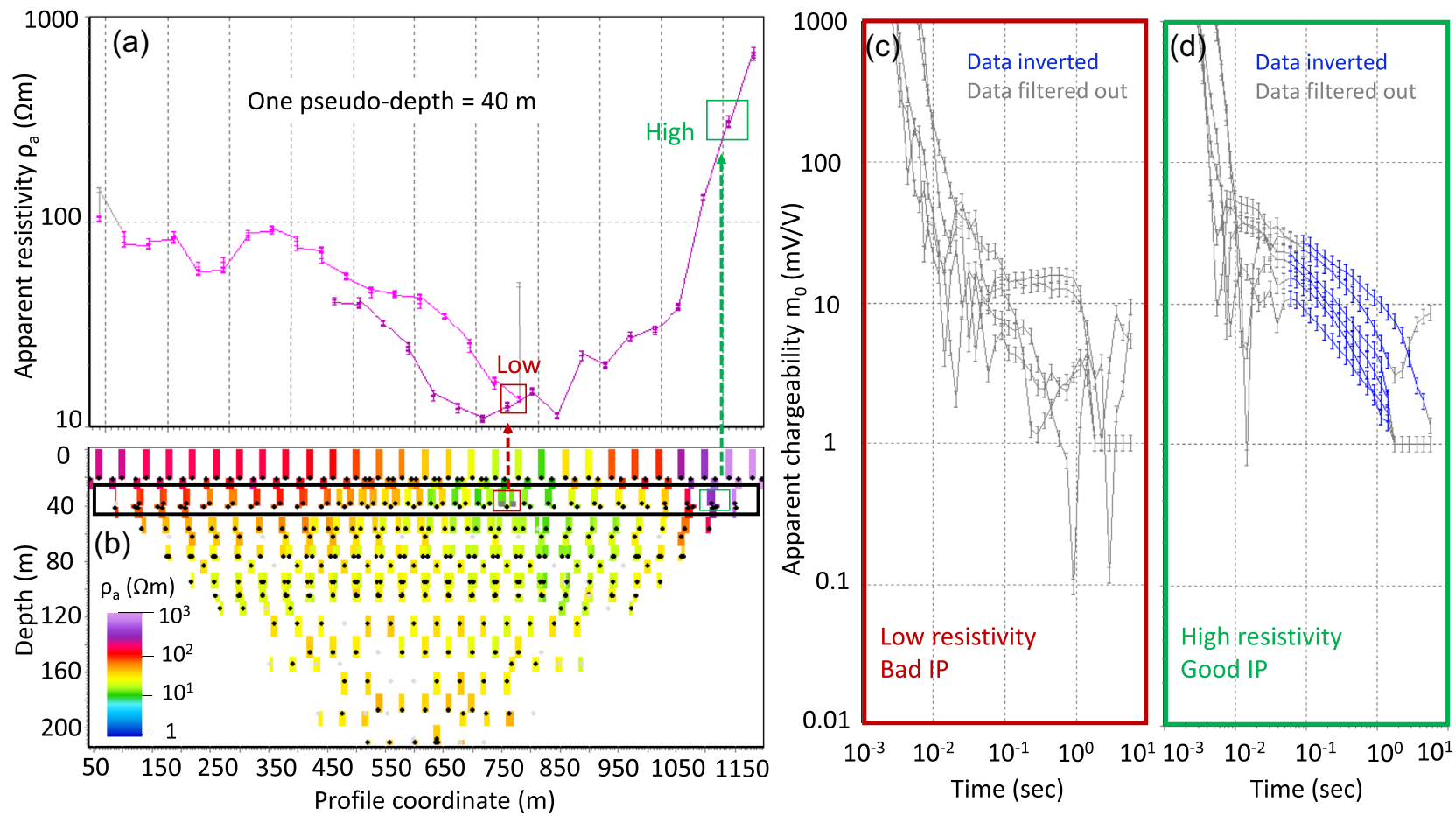

Figure 4. Visualization of the apparent resistivity and chargeability data at profile ISL-5, using the software Aarhus Workbench. Panels (a) and (b) show apparent resistivity, at one pseudo-depth and over the complete pseudo-section, respectively. Panels (c) and (d) show voltage decays (represented as apparent chargeability) as a function of time, for data points selected in (a). Panel (d) corresponds to data points with high resistivity and good quality voltage decays (green rectangle in panel a). Panel (c) corresponds to data points with low resistivity and noisy voltage decays (red rectangle in panel a).

a dimensionless data misfit $\chi$ is calculated, using eq. (4).

$\chi=\sqrt{\frac{1}{N} \sum_{i=1}^{N} \frac{\left(d_{\mathrm{obs}, i}-d_{\mathrm{fwd}, i}\right)^{2}}{\delta_{d_{i}}^{2}}}$,

where $d_{\mathrm{obs}}, d_{\mathrm{fwd}}, \delta_{\mathrm{d}}$ and $N$ are the logarithm of the observed (measured) data, logarithm of the forward prediction, standard deviation of the observed data and number of data points, respectively. Standard deviation of resistivity is estimated as 2 percent of the resistivity value and for IP parameters, it is calculated by eq. (5).

$\delta_{d_{\mathrm{IP}}}=\frac{V_{\text {threshold }}}{V_{\mathrm{IP}}} \frac{1}{\sqrt{\mathrm{stk}}} \frac{1}{\sqrt{\frac{\mathrm{gwd}}{10}}}$,

where $\delta_{d_{\mathrm{IP}}}, V_{\text {threshold }}, V_{\mathrm{IP}}$, stk and $g w d$ are the standard deviation of IP parameters in a given gate, the nominal noise floor for $10 \mathrm{~ms}$ gate width (integration time) and one stack (in $\mathrm{mV}$ ), the voltage value for a given gate (in $\mathrm{mV}$ ), the stack size (dimensionless) and the gate width (in $\mathrm{ms}$ but normalized to $10 \mathrm{~ms}$ so that $\mathrm{gwd} / 10$ is dimensionless), respectively. The parameter $V_{\text {threshold }}$ is adjusted manually until a suitable noise model is obtained for each IP gate.

Negative voltage discharge curves were regularly observed in our field measurements but they could not be correctly fitted by IP inversion, although the option exists in AarhusInv software. Therefore, we attributed these negative data to poor data quality and did not include them in the inversions.

\section{RESULTS}

Different types of data sets are analysed in this section. The complex resistivity inversion models from time-domain field data are presented for each of the three sites separately. KS1, where IP data of best quality are recorded, is presented first. KH3, where the noisiest IP discharge curves are recorded, is presented at last. At KH1 and $\mathrm{KH} 3$, resistivity inversions are compared to in situ resistivity measured in the boreholes with the 16/64 logging tool. Then, laboratory measurement of resistivity and phase-angle, at room temperature, are presented and compared to field inversions and in-situ logs, in order to evaluate the consistency between laboratory and field values.

The investigated area is characterized by a caldera boundary, hydrothermal alteration, large groundwater flow, and is affected by both basaltic and rhyolitic fissure eruptions, as well as volcanotectonic rifting episodes. These features result in large resistivity contrasts, with resistivity as low as a few $\Omega \mathrm{m}$ where active hydrothermal circulations take place, and up to $10^{4} \Omega \mathrm{m}$, corresponding either to the obsidian ridge 'Hrafntinnuhryggur' or to a near-surface layer above the ground water level (Fig. 5). The colour scale used here shows low resistivity in blue.

\subsection{KS1 site: cold and unaltered}

The inversion models at KS1 site are presented in Fig. 6. Profiles ISL-1 and ISL-4 (north of borehole KS1) show a high-resistivity body over the whole section, down to the DOI. Profile ISL-2 (south of borehole KS1) shows a low-resistivity structure on the southeastern edge. Profile ISL-3 is very similar to ISL-2 both in terms of data pseudo-section and inversion models. Inversion results are not shown in Fig. 6 but can be seen in the 3-D view presented in subsection 3.5.

A high MPA is observed at the centre and western edge of ISL-1 and ISL-4: up to $80 \mathrm{mrad}$ at $120 \mathrm{~m}$ depth and $50 \mathrm{mrad}$ at $140 \mathrm{~m}$ depth, respectively (Fig. 6). ISL-2 and ISL-3 show less MPA contrast than 

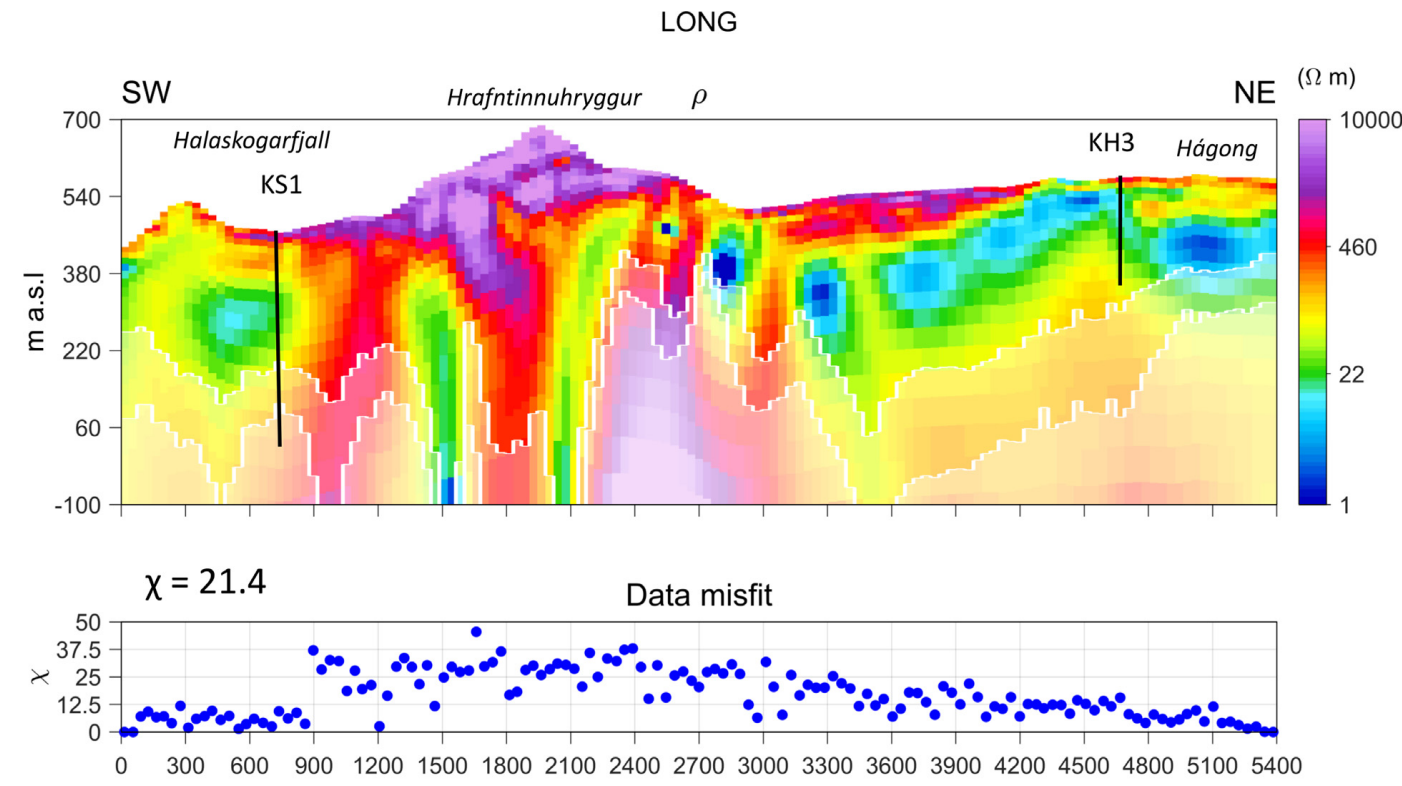

Profile coordinate $(\mathrm{m})$

Figure 5. 2-D resistivity inversion of the LONG profile, showing the overall resistivity structure of the area. The data misfit $\chi$ for each vertical section of the model (spaced every $40 \mathrm{~m}$ ) is given in the lower panel and the average data misfit is also written (see eq. 4). The two white lines in the lower part of the inversion model represent the shallow and deep DOI.

ISL-1 and ISL-4. The low MPA observed at the centre of ISL1 is a local feature, absent on neighbouring profiles. As ISL-1 is the closest profile to KS1 borehole, we cannot rule out an artefact related to the $900 \mathrm{~m}$ long steel casing in this hole.

Short relaxation times, down to $0.02 \mathrm{~s}$ at elevation $400 \mathrm{~m}$ (depth $50 \mathrm{~m}$ ) are observed on profile ISL-1 and, to some extent, ISL-2 and ISL-4 (Fig. 6).

The IP data quality at site KS1 is the best of the three sites, as can be observed on the IP data pseudo-sections, the DOI and the residuals of all profiles.

\subsection{Site KH1: hot and altered}

The inversion results at KH1 site are presented in Fig. 7. The inverted resistivity models from profiles ISL-10, ISL-11 and ISL-12 highlight a central low-resistivity body from the surface to the DOI, with a resistivity in the range $5-10 \Omega \mathrm{m}$ over the whole body. In comparison, the surrounding region is very resistive, up to $10^{4} \Omega \mathrm{m}$ at the surface. The resistivity values obtained from the inversions of ISL-10 and ISL-11 are consistent with electrical logs (16/64) in borehole KH1, located at 17 and $84 \mathrm{~m}$ from the centre of ISL-10 and ISL-11, respectively (Fig. 7).

A layer with high MPA is observed in profiles ISL-11, ISL-12 and, to some extent, ISL-10 (Fig. 7). The high MPA layer is less clear in ISL-10 because the DOI of the MPA model is shallower for this profile. The DOI of the MPA for the three profiles is shallowest at the centre. All the IP data in the low-resistivity body had to be filtered out, due to poor signal quality and the impossibility to fit the voltage discharge curves with IP decays. This explains the 'hole' in the apparent chargeability pseudo-sections of profiles ISL-10, ISL-11 and, to some extent, ISL-12, while the resistivity pseudosections are complete (Fig. 7). The lack of IP data is less pronounced in profile ISL-12, where the resistivity anomaly is slightly reduced compared to profiles ISL-10 and ISL- 11 .
Rather long relaxation times are observed in profiles ISL-10, ISL-11 and ISL-12: up to one second in the depth range 50-100 m (elevation 400-450 m) in profile ISL-12 (Fig. 7).

\subsection{KH3: field results at cold altered site}

Resistivity inversion models at KH3 site are presented in Fig. 8. A thick low-resistivity layer is evidenced in all resistivity models at this site and more generally in the northeastern part of the studied area (Fig. 5 for the LONG profile, Fig. 8 for ISL-5, ISL-7 and ISL-9 and Supporting Information Fig. S5 for ISL-6 and ISL-8). The in-situ resistivity logs $16 / 64$, available between 40 and $120 \mathrm{~m}$, show a similar low-resistivity layer $(10-30 \Omega \mathrm{m})$ at the same depth but thinner ( elevation range 490-530 $\mathrm{m}$ in Fig. 8, corresponding to depth range 55-95 $\mathrm{m}$ ).

\subsection{Comparison to laboratory results}

\subsubsection{Presentation of frequency-domain laboratory results}

The phase-angle of the electrical impedance is the delay between the voltage and the injected current. The phase spectra presented in Fig. 9 show the variations of phase-angle in the frequency range 0.01-10 $0^{4} \mathrm{~Hz}$, for three samples from borehole KH1 (samples L2, L6 and L9) and three from borehole KH3 (samples L117, L119 and L123). The three samples from KH1 are smectite- and pyrite-rich, while the samples from KH3 contain either iron-oxides with no smectite (L117) or less than 0.5 percent pyrite but $\geq 30$ percent smectite (L119, L123). For each sample, the frequency-domain MPA is the maximum of the phase-angle spectrum, at frequencies lower than $10^{4} \mathrm{~Hz}$. In natural volcanic samples presenting a wide variety of mineral textures, with in particular variable grain sizes for metallic minerals, this maximum includes contributions from different polarization processes occurring over different length-scales. 


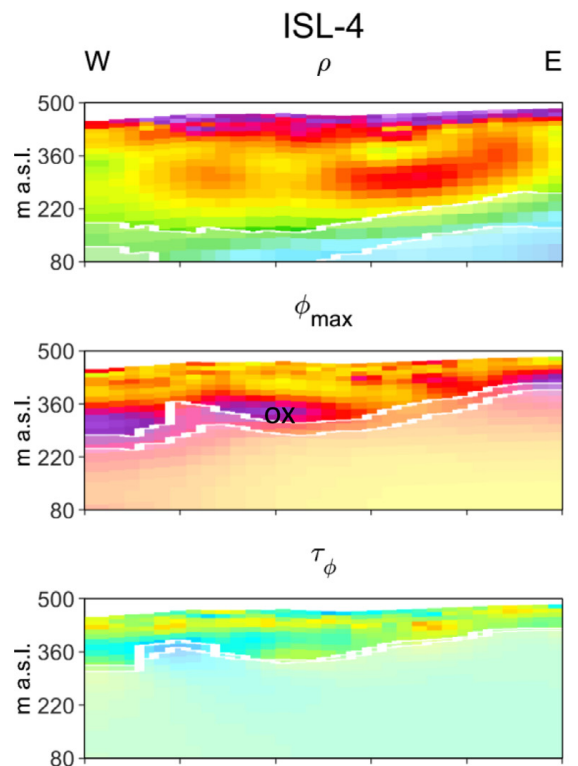

$\rho$ pseudosection, data

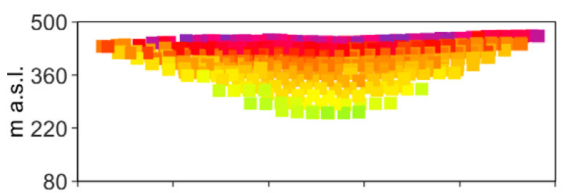

$<\mathrm{M}>$ pseudosection, data
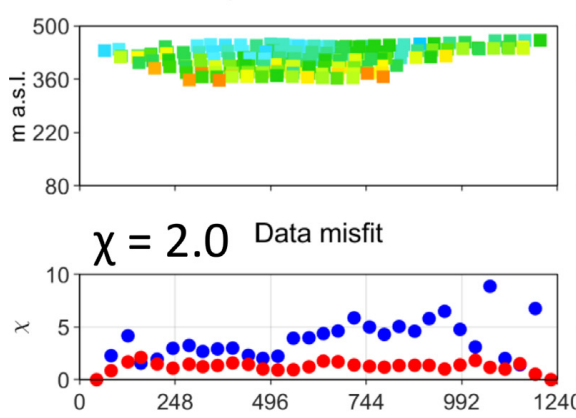

ISL-1

W $\rho$
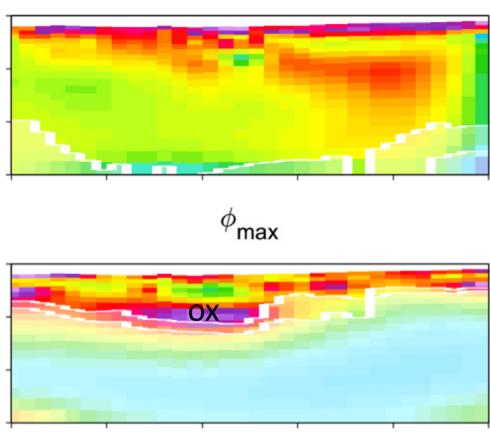

$\tau_{\phi}$

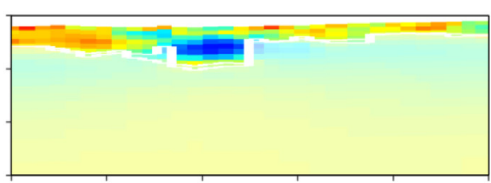

$\rho$ pseudosection, data

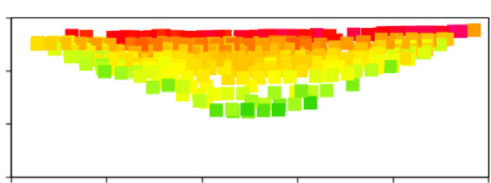

$<\mathrm{M}>$ pseudosection, data

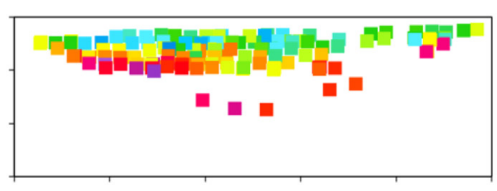

$\chi=3.5$ Data misfit
ISL-2

$\begin{array}{llll}\text { E NW } & \rho & \mathrm{SE} & (\Omega \mathrm{m})\end{array}$
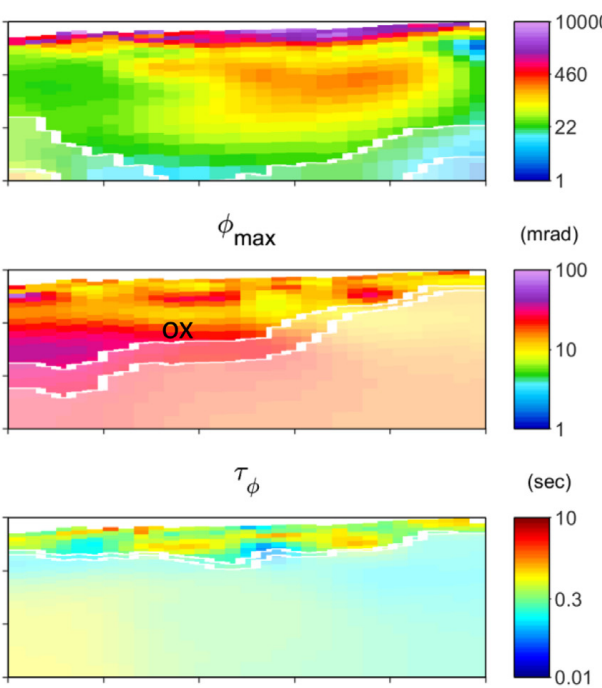

(sec)

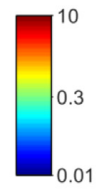

$(\Omega \mathrm{m})$

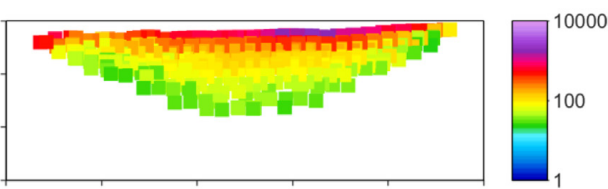

$<\mathrm{M}>$ pseudosection, data

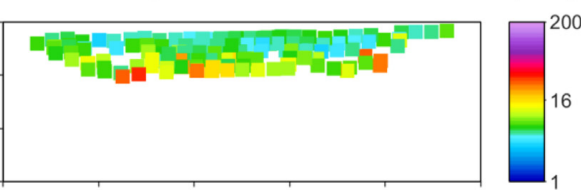

$\chi=2.0$ Data misfit

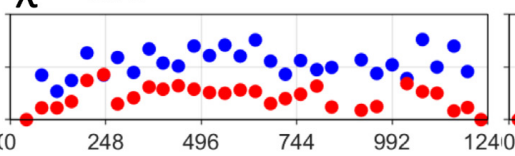

Profile coordinates (m)

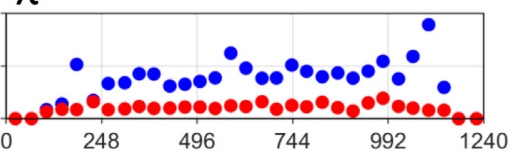

Figure 6. Inversion models for profiles ISL-4, ISL-1 and ISL-2 at KS1 site. Six figures are shown by profile, from top to bottom: resistivity $\rho$ inversion model, MPA inversion model ( $\phi_{\max }$ is the opposite of the maximum phase angle), relaxation time $\tau$ inversion model, resistivity data ( $\rho$ ) pseudo-section, IP data (represented by integral apparent chargeability, $<\mathrm{M}>$ ) pseudo-section, data misfit for resistivity (blue) and IP decays (red). The average data misfits $\chi$ for each profile, including resistivity and IP data misfits are also shown above the bottom panel. The inferred presence of iron-oxides in the high-MPA zones is indicated by 'ox'.

The frequency at which maximum polarization occurs may be related to the grain size distribution of metallic particles (e.g. Wong 1979; Wait 1987; Gurin et al. 2018). Figs S6 and S7 in Supporting Information illustrate the variability of peak frequency (or its inverse, the relaxation time) and grain size distribution of metallic particles among the samples used in this study.

\subsubsection{Consistent field and laboratory resistivity values at the cold altered site (KH3)}

A low-resistivity layer is consistently observed in the depth range 55-95 m (corresponding to elevations $490-530 \mathrm{~m}$ ) in borehole logs and laboratory measurements and at elevations $450-550 \mathrm{~m}$ in inversion of field data at profile ISL-5 (Fig. 10). The discrepancy in thickness and resistivity value of this layer between borehole and laboratory measurements on one side, and inversion of field data on the other side can be explained, to some extent, by a scale effect: the smallest distance between electrodes are a few centimetres in laboratory and boreholes measurements, whereas it is $40 \mathrm{~m}$ in the field. In addition, the equivalence between thickness and resistivity, which is intrinsic to ERT and more generally to geophysical inversion (e.g Johansen 1977; Menke 2012), may also partly explain the different thickness of the conductive layer in the field inversion, compared to borehole logs and laboratory measurements.

\subsubsection{Large resistivity offset at the hot altered site (KH1)}

An offset of about one order of magnitude between laboratory resistivity measurements at room temperature and in-situ borehole logs is observed at KH1 (Fig. 11a). In order to investigate the reason for 


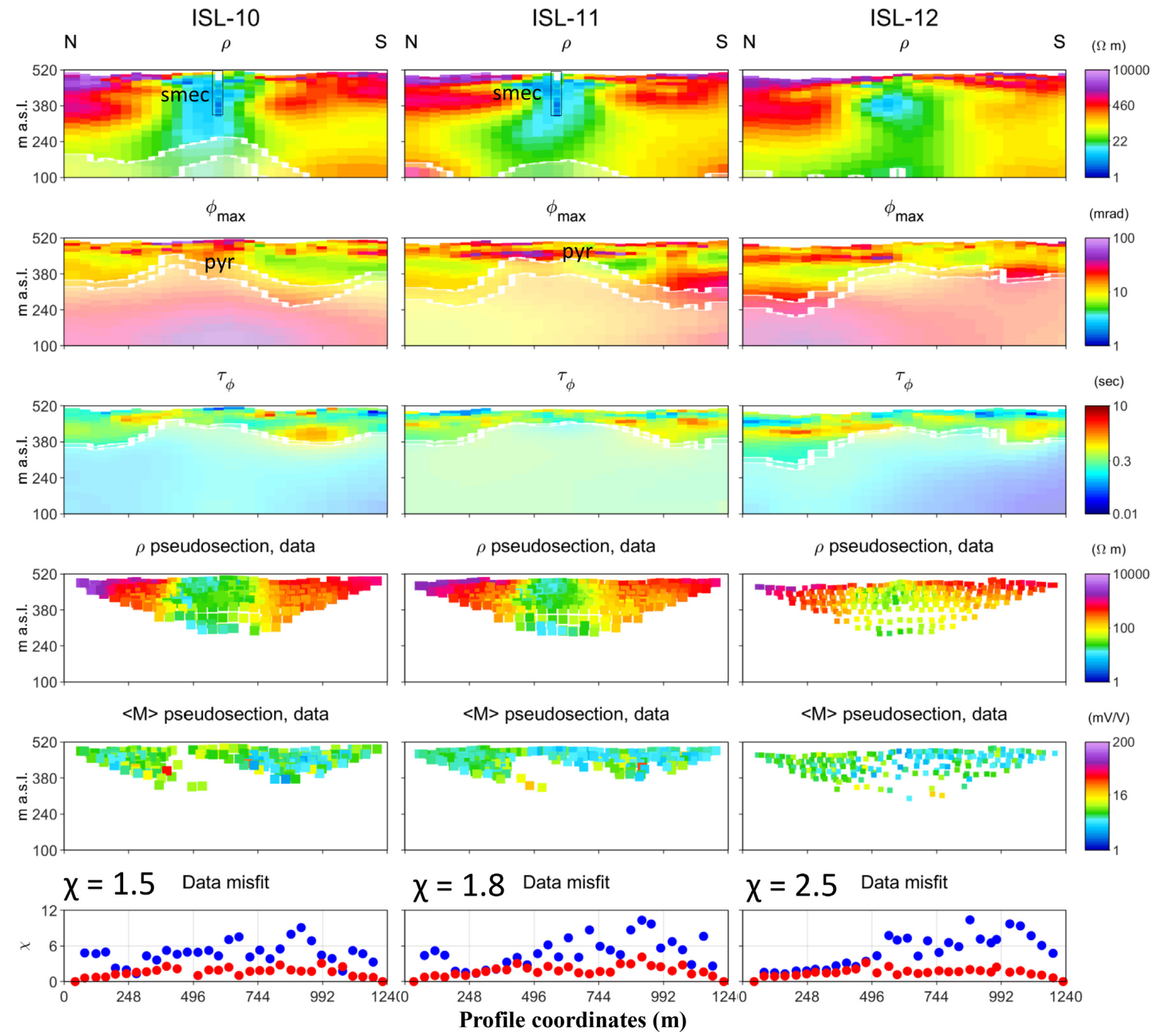

Figure 7. Inversion models for profiles ISL-10, ISL-11 and ISL-12 at KH1 site. Six figures are shown by profile, from top to bottom: resistivity $\rho$ inversion model, MPA inversion model ( $\phi_{\max }$ is the opposite of the maximum phase angle), relaxation time $\tau$ inversion model, resistivity data ( $\rho$ ) pseudo-section, IP data (represented by integral apparent chargeability, $<\mathrm{M}>$ ) pseudo-section, data misfit for resistivity (blue) and IP decays (red). The average data misfits $\chi$ for each profile, including resistivity and IP data misfits are also shown above the bottom panel. The borehole resistivity log (16 inch) in KH1 is shown at the centre of ISL-10 and ISL-11 resistivity inversion models (real distances are 17 and $84 \mathrm{~m}$, respectively), with the same colour scale. The white rectangle on the top of the borehole indicates that no data were available. The inferred presence of smectite and pyrite in the low-resistivity and high-MPA zones are indicated by 'smec' and 'pyr', respectively.

this offset between laboratory and in-situ resistivity measurements, we build a 'room temperature' resistivity model of the borehole, based on the lithology and the NN logs. The analysed samples at KH1 are classified into five types of lithological layers, using petrographic observations of the core samples, as well as lithological logs presented by Gudmundsson (1991). This classification has resulted in a simplified lithological model of the borehole geology, presented in Supporting Information Fig. S8.

We observe that laboratory resistivity values of core samples fall in a similar range for samples sharing a common lithological type (Table 1). This is consistent with the fact that, for these samples, the electrical resistivity is controlled by the quantity of smectite and the porosity, which are themselves mainly controlled by the original lithology (Lévy et al. 2018). In other words, the fracture system allows hot water to flow everywhere but, in the end, the glassy and porous layers (tuff, hyaloclastite) are the most altered while the crystalline and dense layers (basaltic intrusion, central lava flow, ignimbrite) are the least altered. A conductivity value was estimated for each layer, using the average conductivity of three to six samples belonging to each lithological layer. An average resistivity, with associated standard deviation, is then calculated for each layer (Table 1) and used to build the lithological resistivity $\log$ at room temperature (continuous blue line in Fig. 11a). 
ISL-5
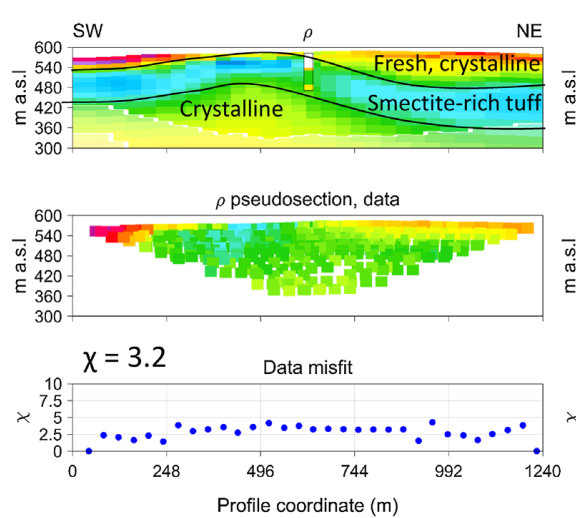

ISL-7
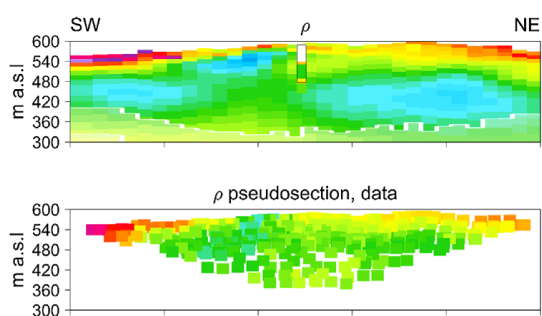

$x=2.9$

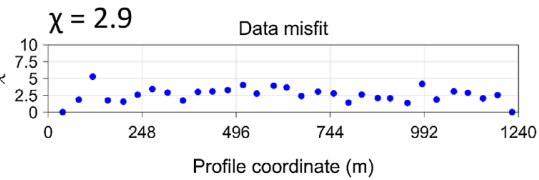

ISL-9
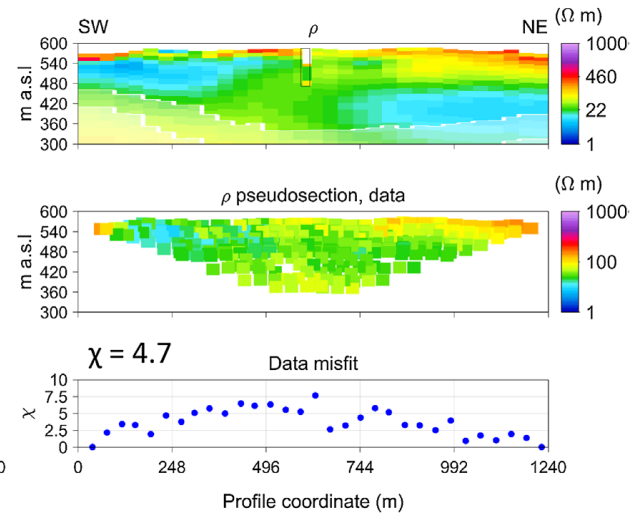

Figure 8. Resistivity inversion models and comparison to borehole data at KH3 site for parallel profiles ISL-5, 7 and 9, with $100 \mathrm{~m}$ distance in-between. The two black lines delimit a low-resistivity layer, interpreted as smectite-rich tuff. The data misfit $\chi$ for each vertical section of the model (spaced every $40 \mathrm{~m}$ ) is given in the lower panel and the average data misfit is also written (see eq. 4). The borehole resistivity $\log (16$ inch) in KH3 is shown at the centre of ISL-5, ISL -7 and ISL-9 resistivity inversion models (real distances are 174, 78 and $32 \mathrm{~m}$, respectively), with the same colour scale. The green layer corresponds to the low-resistivity layer in the borehole. The white rectangle indicates that no data were available.

We observe that the lithological resistivity log at room temperature $\left(22-25^{\circ} \mathrm{C}\right)$ has an average resistivity about one order of magnitude higher than in-situ borehole observations (3-6 $\Omega \mathrm{m})$ and inversion results $(5-10 \Omega \mathrm{m})$. This holds true even when a large range of pore fluid conductivity is considered (see Fig. 11a for the range $0.02-0.1 \mathrm{~S} \mathrm{~m}^{-1}$ represented by error bars). After correction for the effect of temperature, using a coefficient of $0.06^{\circ} \mathrm{C}^{-1}$, the lithological resistivity log overlaps in-situ borehole observations (Fig. 11b).

\subsubsection{Qualitative comparison of IP parameters at KHI}

The timescale of polarization phenomena investigated with field measurements falls in the range $0.01-8 \mathrm{~s}$. This means that only polarization processes with a time constant within this interval can be fully observed. This range is limited by (i) the high-frequency noise in the early recording times, mostly due to electromagnetic induction effects and (ii) the maximum $T_{\text {off }}=8 \mathrm{~s}$, which was used in the field. The frequency-range corresponding to this time-range is approximately $0.1-100 \mathrm{~Hz}$. The maximum polarization of core samples from borehole KH1 (hot site), measured in the laboratory in the frequency range $10^{-2}-10^{4} \mathrm{~Hz}$, occurs at higher frequencies for many samples, reaching $10 \mathrm{kHz}$ in some cases (e.g. sample L9 in Fig. 9). Therefore, the polarization observed in the field can be significantly lower than the maximum polarization.

This is a drawback of field IP measurements (in both timedomain, TDIP, and frequency-domain, FDIP), compared to laboratory FDIP measurements. Increasing the distance between electrodes, necessary to target deeper levels, enlarges the frequencyand time-ranges in which EM effects are dominant, in FDIP and TDIP, respectively (Fiandaca 2018). In the field study by Pelton et al. (1978), a frequency-range as large as $10^{-2}-10^{5} \mathrm{~Hz}$ was investigated with FDIP but using $1 \mathrm{~m}$ spacing between electrodes and thus targeting only exposed mineralization at the surface.

Profile ISL-11 is chosen for comparison between field and laboratory MPA measurements, because the DOI at the centre of ISL-11 is deeper than in ISL-10 (Fig. 7). Many samples in borehole KH1 reach their maximum polarization at times shorter than $10 \mathrm{~ms}$ (frequency higher than $100 \mathrm{~Hz}$, see Fig. 9). Since only polarization occurring on timescales larger than 10-20 ms can be resolved by our TDIP field measurements, we can only observe a part of the maximum polarization with these measurements. Therefore, the laboratory MPA taken at frequencies below $100 \mathrm{~Hz}$ is used for comparison to the inverted MPA.

In the depth-range investigated (above DOI), the inverted MPA is fairly consistent with the laboratory MPA taken below $100 \mathrm{~Hz}$ (Fig. 12). In particular, the high MPA layer at 40-50 m depth corresponds to the high MPA observed in samples L2 and L6. However, frequency-domain laboratory MPA are generally higher than inverted MPA, at a given depth. The laboratory MPA are shown with error bars, corresponding to a large range of pore fluid conductivity $\left(0.02-0.5 \mathrm{~S} \mathrm{~m}^{-1}\right)$, to account for possible variations of local pore water conductivity. Note that the typical in-situ fluid conductivity at Krafla is $0.078 \mathrm{~S} \mathrm{~m}^{-1}$, according to Flóvenz et al. (2005).

\subsection{Joint consideration of the results at KH1 and KS1 sites}

A 3-D visualization of the resistivity inversions at KH1 and KS1 sites is presented in Fig. 13. At KH1, the three parallel profiles, as well as the perpendicular profile, indicate a low-resistivity structure around borehole KH1, with a cylindrical shape. At KS1, inversion models from the four parallel profiles indicate an overall resistive environment. A low-resistivity structure is observed in the southeastern edge of ISL-2 and ISL-3 and corresponds to the up-flow zone at KH1 site, under Leirholl (Figs $1 \mathrm{~b}$ and 13).

A 3-D visualization of MPA inversions is presented in Fig. 14. As opposed to resistivity, MPA inversions do not indicate a clear difference between KH1 and KS1 sites. A high MPA is consistently observed on the three parallel profiles at KH1, at shallow depth, as well as on two of four parallel profiles at KS1 (red-purple colours).

A 3-D visualization of relaxation time inversions is presented in Fig. 15 and shows that the high MPA layers at KH1 are generally associated to long relaxation times ( $1 \mathrm{~s}$, in red), whereas layers of very short relaxation time $(0.01 \mathrm{~s}$, in blue) are observed at KS1 site. Although a contrast exists between the two sites, care must be taken when interpreting the relaxation time values, due to the limited time-range resolved with the TDIP measurements, and the limited depth of investigation of the relaxation time (shallower than for the resistivity and the MPA). 

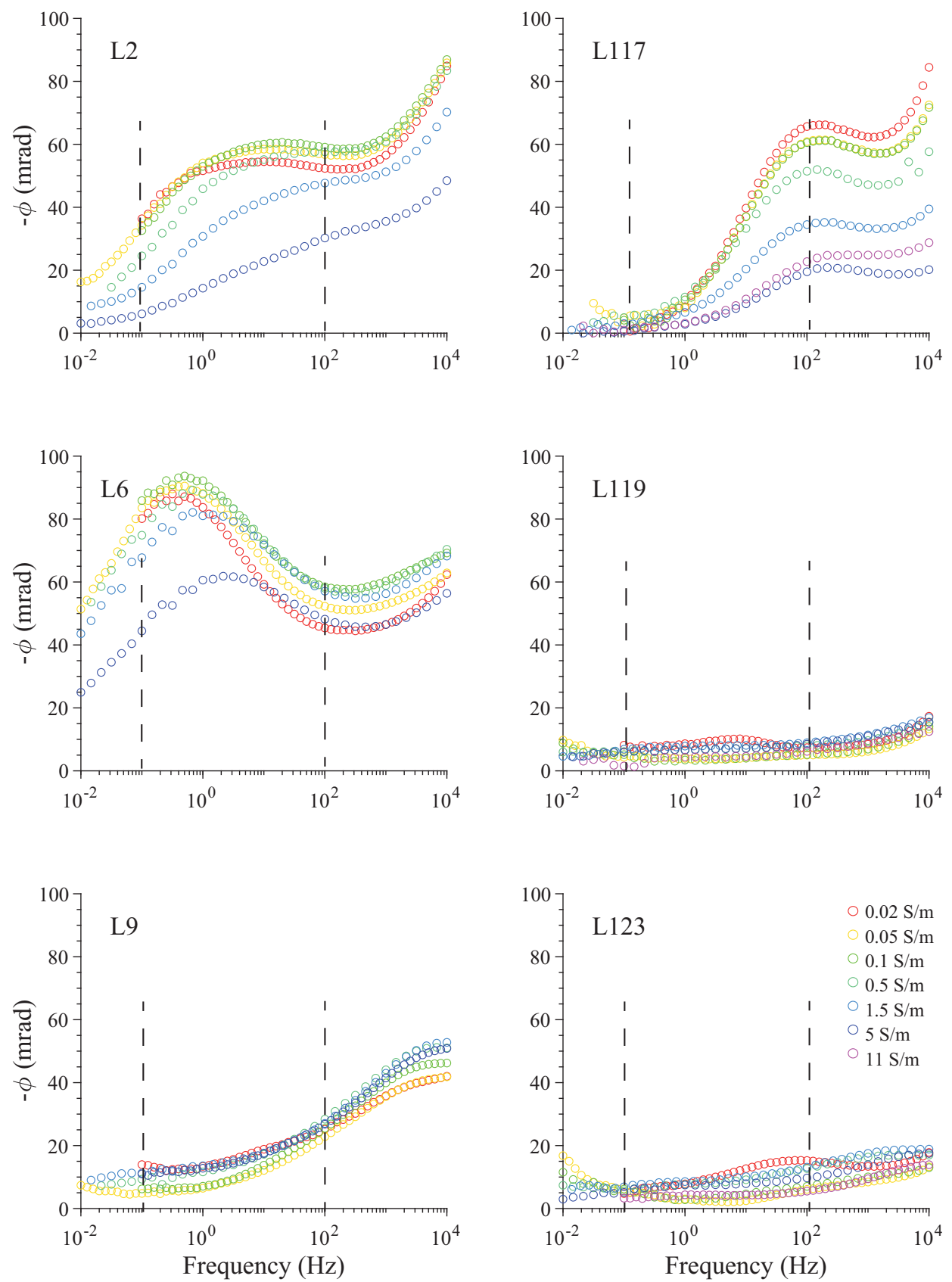

Figure 9. Phase spectra for samples L2, L6, L9 (KH1) and L117, L119, L123 (KH3) measured with laboratory frequency-domain IP. The different colours correspond to different pore fluid conductivities. The same colour scale as for L123 is used for all samples. The vertical lines correspond approximately to the time range investigated in our time-domain field measurements, in the most optimistic scenario: $0.01-8 \mathrm{~s}$, corresponding to $0.1-100 \mathrm{~Hz}$. Samples L119 and L123 contain less than 0.5 vol. per cent of metallic particles (pyrite) but more than 30 vol. per cent smectite. Sample L117 contains 1.8 vol. per cent iron-oxides while samples L2, L6 and L9 contain 2.5-5.5 vol. per cent pyrite.

A classification of the three different sites, based on their complex electrical structure, mineralogy and hydrothermal activity, is summarized in Table 2.

\section{INTERPRETATIONS AND DISCUSSION}

In this section, relationships between resistivity, MPA, relaxation time and mineralogy, resulting from frequency-domain laboratory observations, are used to support the interpretation of field inversions.

\subsection{Rapid spatial variations of resistivity signatures along the caldera boundary}

At $\mathrm{KH} 3$, the low-resistivity body is attributed to an abundance of smectite, with up to 50 wt. percent smectite found in samples L119 to L123 (Lévy et al. 2018), whose depths correspond to the low-resistivity layer observed with borehole logs (Table A1 in Appendix). The present temperature in borehole $\mathrm{KH} 3$ is lower than $50{ }^{\circ} \mathrm{C}$ down to $400 \mathrm{~m}$ (Fig. 2b) but smectite could have formed during past regional hydrothermal circulations with a rather horizontal flow direction, coming from inside the caldera, or simply by slow 


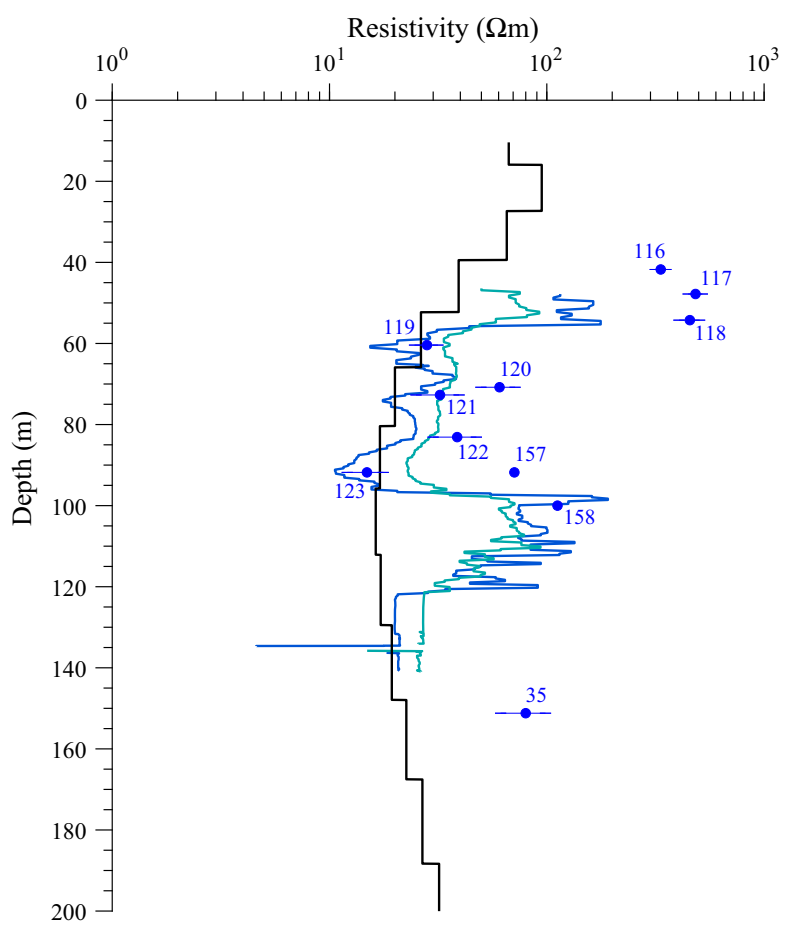

Figure 10. Comparison of resistivity values obtained from laboratory, insitu borehole logs and inversion of profile ISL-5. The laboratory resistivity measurements at $1 \mathrm{~Hz}$ (blue circles) are given with an error bar corresponding to variations of pore water conductivity in the range $0.02-0.1 \mathrm{~S} \mathrm{~m}^{-1}$. No error bars are shown for samples 157 and 158 because only one measurement, at pore fluid conductivity $0.07 \mathrm{~S} \mathrm{~m}^{-1}$, was made. The 16 -inch and 64-inch borehole resistivity logs are represented by blue and green lines, respectively. The inversion model is shown with the black line.

glass replacement without any active circulation. Pyrite and calcite are sporadically observed in fracture fillings in the low-resistivity layer, indicating that hydrothermal activity has occurred, but to a small extent only. We thus interpret the low-resistivity layer, observed in all profiles of the northeastern part of the studied area (Figs 5, 8 and Supporting Information Fig. S5), as a consistent geological layer composed of very altered volcanic glass.

At KH1, a low-resistivity body with a cylindrical geometry is observed (Fig. 13). We interpret this shape as the result of the crossing of two orthogonal faulting directions (Fig. 1): the rifting NNE-SSW direction, consistent with the rhyolite eruption forming the obsidian ridge Hrafntinnuhryggur, and a concentric faulting system, typical of caldera rim structures, at the southern edge of the caldera (see e.g. Sigmundsson 2006 for more details on the geology). We suggest that the intersection of these two geological features at KH1 site has created a high-permeability up-flow zone, and that intense alteration resulting in large smectite volumes is the primary cause for the low resistivity. Hydrothermal plumes of similar shape have been observed at the intersection of orthogonal faulting structures at other volcanoes (Gresse et al. 2017). Moreover, surface alteration at this site suggests the presence of hot springs and even fumaroles at some point: white soft clays, gypsum and silica sinters are found at Leirholl ('clay-hill' in Icelandic), around borehole KH1. These minerals are witnesses of steam up-flow reaching the surface. The hydrothermal plume at KH1 may relate to a deep low-resistivity anomaly observed at $1750 \mathrm{~m}$ depth in 3-D inversions of MT data in the same area, named Sandabotnaskaro, around the southern caldera rim (Árnason \& Magnússon 2001). However, the shallow up-flow observed with ERT data, and correlated to geological and tectonic features, is not resolved with 1-D inversion of TEM data (Rosenkjaer et al. 2015). Although hydrothermal activity has faded out, $\mathrm{KH} 1$ is still relatively hot today at the shallow depths investigated $\left(170^{\circ} \mathrm{C}\right.$ at $200 \mathrm{~m}$ depth, Fig. $\left.2 \mathrm{c}\right)$.

At KS1, the overall high resistivity observed at the shallow depths investigated (down to $300 \mathrm{~m}$ ) coincides with the presence of fresh, recent and unaltered basalt and low temperatures (Gudmundsson et al. 2007). Intense hydrothermal activity is yet present at $\mathrm{KS} 1$ site below $1 \mathrm{~km}$ : the temperature reaches $300^{\circ} \mathrm{C}$ at $1.2 \mathrm{~km}$ and $350{ }^{\circ} \mathrm{C}$ at $2.5 \mathrm{~km}$ (Fig. 2a). These deep hydrothermal circulations, buried under recent lava layers at KS1 site, are probably connected to the up-flow at KH1 site. The recent lava flow at KS1 site, which is not observed at $\mathrm{KH} 1$ site, might have been stopped before reaching $\mathrm{KH} 1$. In this case, it could have caused subsidence of the ground at KS1 site but up-lift at KH1 site. Finally, a low-resistivity body below $250 \mathrm{~m}$ depth is observed in resistivity inversions at KS1 site and is particularly visible in the southeastern part of the LONG profile (Fig. 5). Future ERT studies in the area of Hvíthólar (west of Sandabotnaskard) could help characterize the tectonic features in the southern Krafla caldera.

\subsection{Interpretation of observed high MPA (KS1 and KH1)}

In the southern part of the caldera, we observe two high-MPA formations but associated with a different range of resistivity (Figs 13 and 14). These two types of complex electrical structures correspond, based on laboratory observations, to pyrite-rich versus magnetiterich zones (Fig. 16). An abundance of iron-oxides, such as magnetite, corresponds to fresh unaltered basalts, whereas an abundance of pyrite mostly corresponds to basaltic rocks affected by hydrothermal circulation (e.g. Lévy et al. 2019). These two different geological contexts would be responsible for the different resistivity range, despite the similar semi-conducting properties of pyrite and magnetite. Based on this discrimination method, we attribute the high-MPA and low-resistivity observed at KH1 to the presence of pyrite, and the high-MPA and high-resistivity at KS1 to iron-oxides.

The presence of pyrite in the high-MPA layer of KH1 is confirmed by three samples coming from KH1 at the relevant depths and analysed in the laboratory: L2, L6 and L9 have a volume fraction of pyrite ranging from 2.5 to 5.5 per cent. The presence of iron-oxides and absence of pyrite in borehole KS1 above $350 \mathrm{~m}$ is confirmed by the drill-cutting analyses (Gudmundsson et al. 2007).

The relaxation time can also be used, to some extent, as a discriminating factor between pyrite and iron-oxides. Pyrite crystals formed by hydrothermal circulations are usually more connected than small and disseminated iron-oxides formed during primary magmatic crystallization. Since connected metallic particles are expected to have longer relaxation time than disseminated metallic particles (Pelton et al. 1978), pyrite-rich layers are expected to have longer relaxation times than magnetite-rich layers (see e.g. Figs S6 and S7 in Supporting Information). Relaxation times are generally shorter at KS1 site than KH1 site (Fig. 15). We suggest that pyrite is the main element responsible for high MPA at KH1, while magnetite plays the same role at $\mathrm{KS} 1$, based on the relaxation time values. However, the DOI for the relaxation time is always the shallowest of all the IP parameters (Madsen et al. 2017), so that this parameter is not very constrained by the model in the conductive plume area (Figs 7 and 15).

An effect of the $900 \mathrm{~m}$ deep casing on the inversion parameters at 
(a)

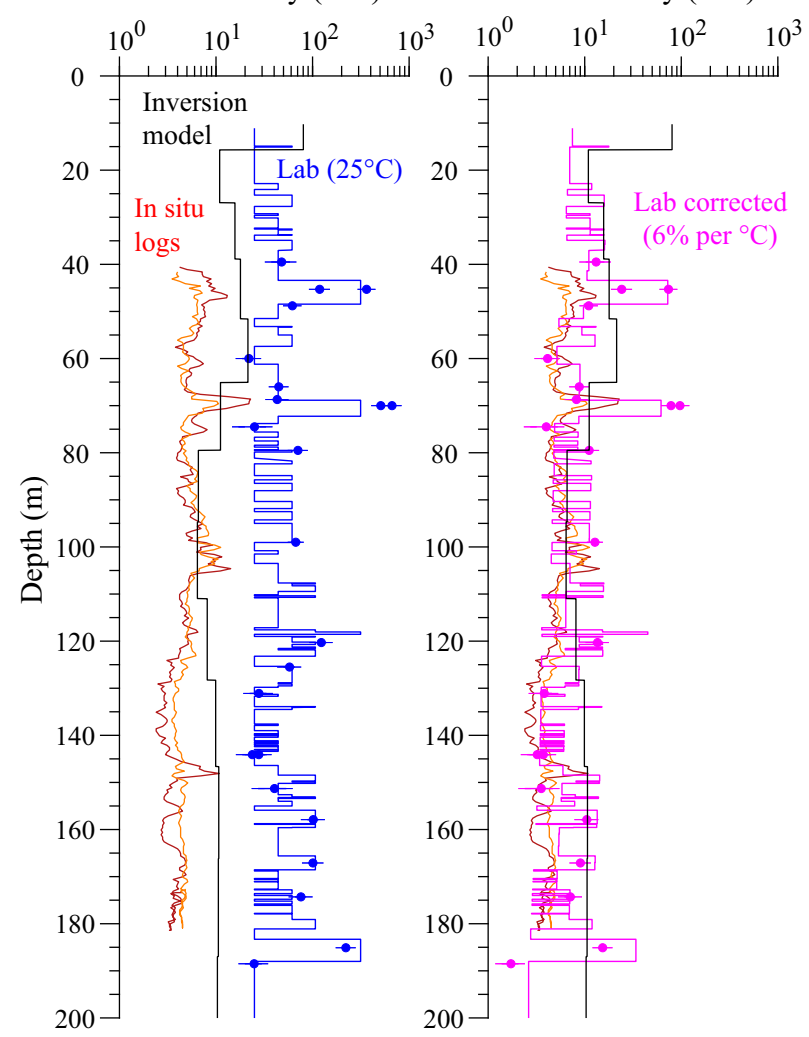

Figure 11. Comparison of resistivity values from laboratory, lithological resistivity $\log$, borehole $\operatorname{logs}$ and inversion of field data at $\mathrm{KH} 1$ site. Panel (a) shows original laboratory resistivity values for each sample, measured at $1 \mathrm{~Hz}$, at pore fluid conductivity in the range $0.02-0.1 \mathrm{~S} \mathrm{~m}^{-1}$ (blue filled circles with error bars), together with the lithological resistivity $\log$ at $25^{\circ} \mathrm{C}$ and pore fluid conductivity $0.05 \mathrm{~S} \mathrm{~m}^{-1}$ (blue line). The lithological resistivity $\log$ is further described in Table 1 and Supporting Information Fig. S8. Also shown are in-situ borehole logs 16/64 (dark red and orange lines). Panel (b) shows laboratory resistivity values (pink filled circles with error bars) and lithological resistivity log (continuous pink line) after correction for the effect of temperature using the coefficient $0.06^{\circ} \mathrm{C}^{-1}$, obtained by fitting in-situ data using eq. (6).

Table 1. Five types of lithological layers in borehole $\mathrm{KH} 1$ and their electrical resistivity. Average values and standard deviation within each group are given, based on laboratory resistivity of three to six samples, measured at room temperature $\left(22-25^{\circ} \mathrm{C}\right)$. A range of resistivity values is considered for each sample, corresponding to the range of pore water conductivity $0.02-$ $0.1 \mathrm{~S} \mathrm{~m}^{-1}$, in order to evaluate the influence of possible local variations in salinity around the average salinity at Krafla (corresponding to a pore water conductivity at $25^{\circ} \mathrm{C}$ of $0.078 \mathrm{~S} \mathrm{~m}^{-1}$ according to Flóvenz et al. 2005).

\begin{tabular}{lccc}
\hline Litho layer & Type & $\rho_{\text {avg }}(\Omega \mathrm{m})$ & $\rho_{\text {std }}(\Omega \mathrm{m})$ \\
\hline A & Dyke, ignimbrite & 289 & 58 \\
B & Basaltic intrusion & 94 & 24 \\
C & Unaltered lava/breccia & 57 & 14 \\
D & Altered lava/breccia & 37 & 13 \\
E & Hyaloclastite / tuff & 19 & 7 \\
\hline
\end{tabular}

KS1 cannot be ruled out. For example the low-MPA anomaly, only observed in one profile (ISL-1, see Fig. 14), suggests the presence of a small structure, such as conductive steel casing. With $40 \mathrm{~m}$ spacing between electrodes, the resolution is much coarser than the casing thickness (few centimetres). Forward calculation of the

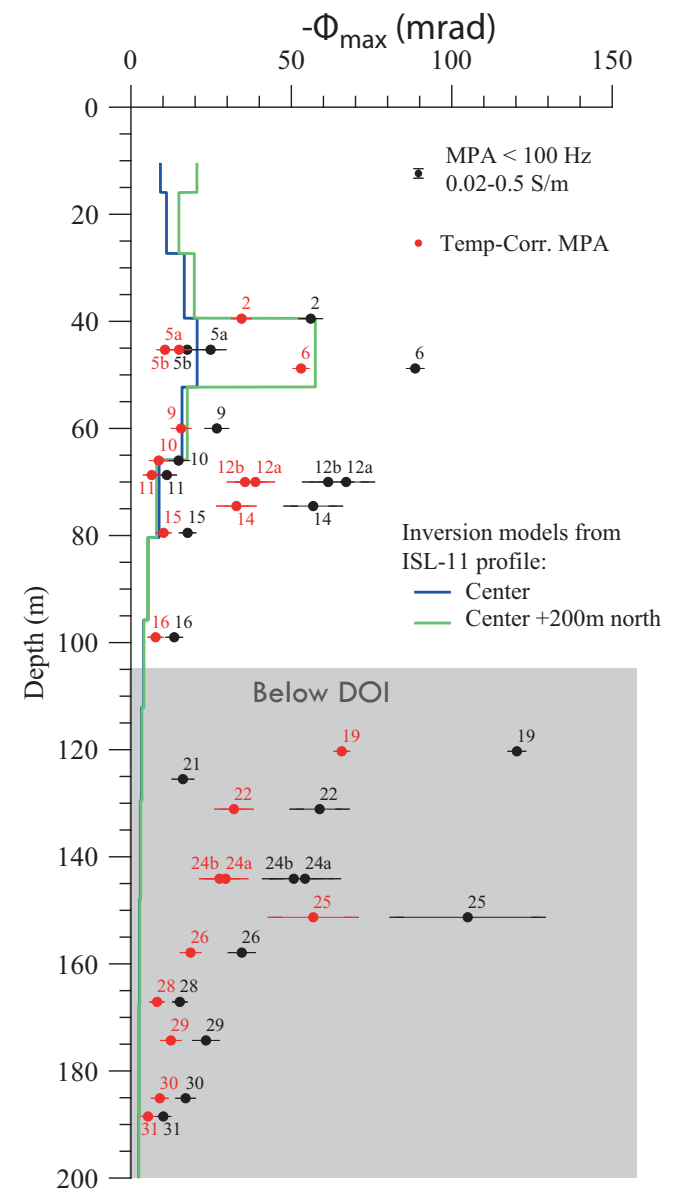

Figure 12. Comparison of MPA obtained with laboratory frequency-domain measurements of samples from borehole KH1 and inversion of profile ISL11 (time-domain). The two coloured lines correspond to the vertical models at the centre and $200 \mathrm{~m}$ to the North, along profile ISL-11. The laboratory MPA, determined in the range $0.1-100 \mathrm{~Hz}$, are shown with filled black circles with horizontal error bars corresponding to variations with fluid conductivity, in the range $0.02-0.5 \mathrm{~S} \mathrm{~m}^{-1}$. The temperature-corrected laboratory MPA, using eq. (B2) presented in Appendix, are shown with red filled circles.

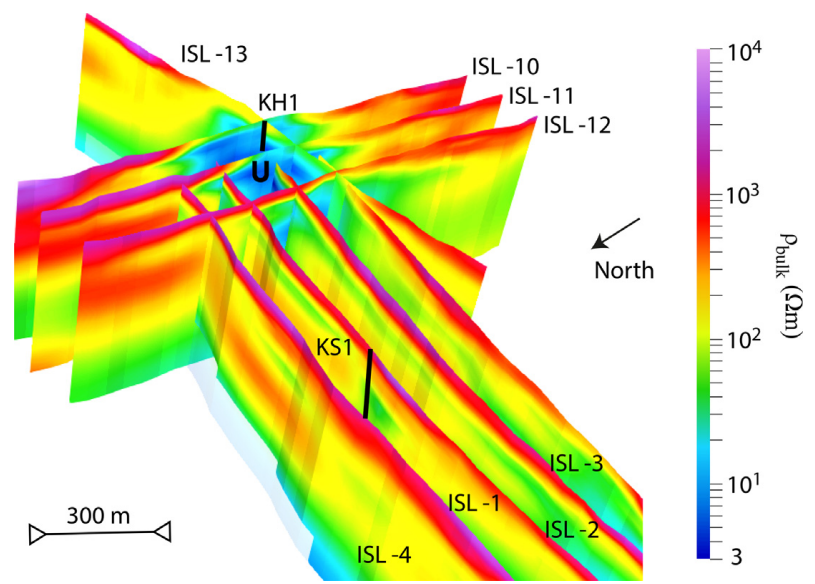

Figure 13. 3-D visualization of the four resistivity profiles at KH1 (ISL-10, 11,12 and 13) and four intersecting resistivity profiles at KS1 (ISL-4, 1, 2 and 3). The zone marked ' $U$ ' corresponds to the smectite-rich low-resistivity plume-like structure, interpreted as an up-flow zone. The inversion results below DOI are transparent. All sections displayed are about $300 \mathrm{~m}$ high. 


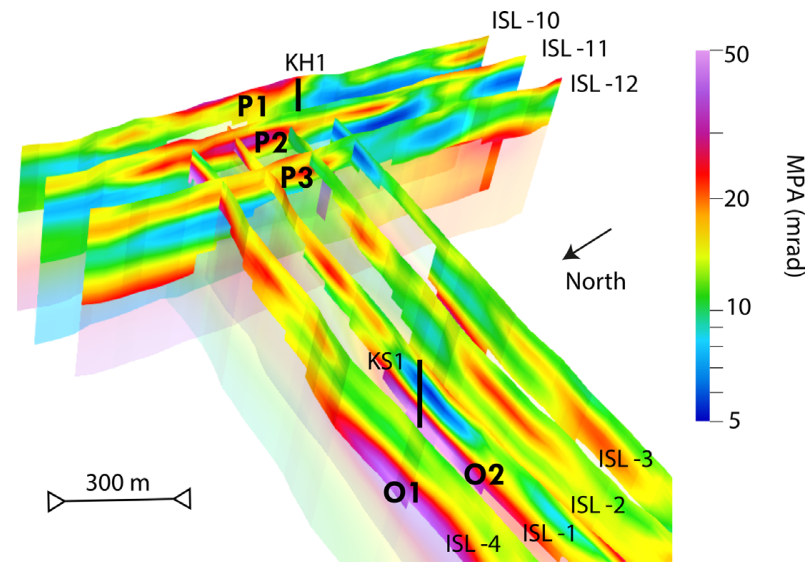

Figure 14. 3-D visualization of the three parallel MPA profiles at KH1 (ISL10,11 and 12) and four intersecting MPA profiles at KS1 (ISL-4, 1, 2 and 3). The areas marked $\mathrm{P} 1$ to $\mathrm{P} 3$ indicate the inferred presence of pyrite, while the areas marked $\mathrm{O} 1$ and $\mathrm{O} 2$ indicate the inferred presence of iron-oxides.

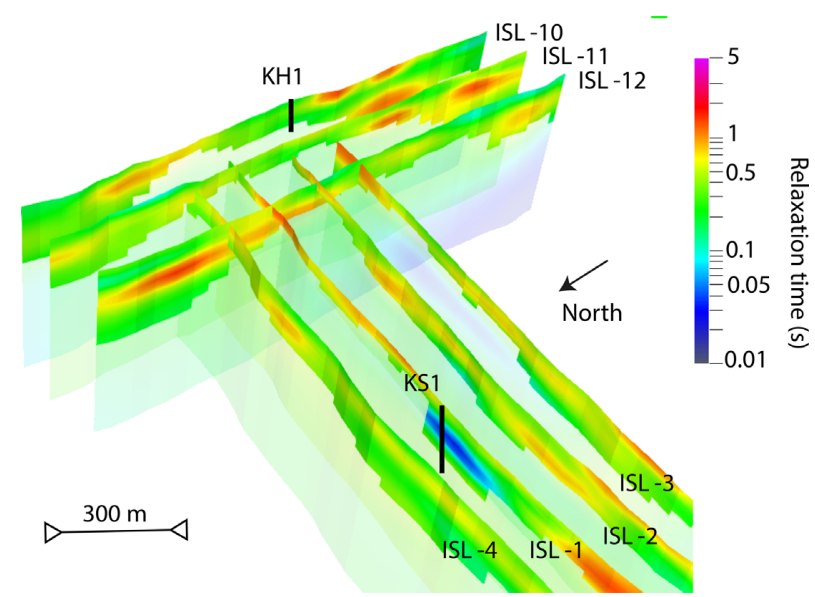

Figure 15. 3-D visualization of the relaxation time inversions for the same profiles as in Fig. 14. Three parallel at KH1 (ISL-10, 11 and 12) and four intersecting profiles at KS1 (ISL-4, 1, 2 and 3).

casing effect would require a refined mesh around the casing, which might be possible with finite elements modelling.

\subsection{Influence of in-situ temperature on resistivity and MPA}

At $\mathrm{KH} 3$, resistivity resulting from field inversions, borehole logs and laboratory are consistent (Fig. 10). At KH1, resistivity values obtained from field inversions fall in the same range as borehole logs but a significant offset exists between field and in-situ borehole logs on one hand and laboratory measurements on the other hand (Figs 7 and 11). The range of resistivity observed in the field is also lower than resistivity measurements on pyrite-rich samples at room temperature (Fig. 16).

We first investigate the possible effect of a hot pore fluid at $\mathrm{KH} 1$, with a fluid composition realistic for a low-salinity geothermal system (corresponding to a fluid conductivity $\sigma_{\mathrm{f}}$ of up to $0.1 \mathrm{~S} \mathrm{~m}^{-1}$ at $25^{\circ} \mathrm{C}$ ). We use eq. (6) to estimate the temperature effect on resistivity (e.g. Arps 1953; Kristinsdóttir et al. 2010).

$\frac{\rho^{\prime}\left(T_{0}\right)}{\rho^{\prime}(T)}=1+\alpha_{\rho^{\prime}}\left(T-T_{0}\right)$, where $\mathrm{T}$ and $T_{0}$ are the in-situ temperatures (presented in Fig. 2) and room temperature in ${ }^{\circ} \mathrm{C}$, respectively, $\alpha_{\rho^{\prime}}$ is the correction coefficient in ${ }^{\circ} \mathrm{C}^{-1}$ and $\rho$ ' is the resistivity in $\Omega \mathrm{m}$.

The coefficient $\alpha_{\rho^{\prime}}=0.02^{\circ} C^{-1}$ suggested by Arps (1953) for water, corresponding to a decrease of resistivity of 2 per cent per ${ }^{\circ} \mathrm{C}$, would correspond to $\rho_{\mathrm{f}}=2.5 \Omega \mathrm{m}$ for a temperature of $180^{\circ} \mathrm{C}$. With formation factors $F$ mostly in the range 30-200 (Lévy et al. 2018), the minimum $\rho_{\mathrm{f}}$ would correspond to a minimum rock resistivity $\rho_{\text {bulk }}$ of at least $50 \Omega \mathrm{m}$, using Archie's law $\rho_{\text {bulk }}=F \rho_{\mathrm{f}}$ (Archie 1942), which is much higher than the 3-6 $\Omega$ m observed. On the other hand, if a local increase of salinity was the explanation for an average rock resistivity of $5 \Omega \mathrm{m}$, the fluid would need to have a resistivity of at most $\rho_{\mathrm{f}}=\frac{\rho_{\text {bulk }}}{F}=\frac{5}{30}=0.17 \Omega \mathrm{m}$ in average. It would correspond to a fluid resistivity of $0.4 \Omega \mathrm{m}$ at $25^{\circ} \mathrm{C}$, considering an average insitu temperature of $100^{\circ} \mathrm{C}$, which is much smaller than the $13 \Omega \mathrm{m}$ (conductivity $0.078 \mathrm{~S} \mathrm{~m}^{-1}$ ) measured by Flóvenz et al. (2005). Thus the sole effect of a hot pore fluid cannot explain the lower resistivity observed in the field.

As a consequence, we suggest that the observed lower in-situ resistivity is also due to a temperature effect on the clay minerals and not only on the fluid. The experimental value of temperaturecorrection factor, compiled from data on clay-rich sands measured by Vinegar \& Waxman (1984), $0.033^{\circ} \mathrm{C}^{-1}$, is yet not sufficient to explain the resistivity offset between laboratory and field. We calculated that a coefficient of $0.06{ }^{\circ} \mathrm{C}^{-1}$ is necessary to explain the resistivity offset, by adjusting the lithological resistivity log at room temperature to the in-situ borehole logs (Fig. 11b). Variations of this coefficient with lithological differences could be expected but this value is generally consistent with experimental results by Kristinsdóttir et al. (2010) on core samples from borehole KH1, heated up to $250^{\circ} \mathrm{C}$, as well as experimental results by Flóvenz et al. (1985) and Nono et al. (2018) on core samples from the Icelandic geothermal fields of Laugar, Reykjanes and Nesjavellir. We thus suggest that the low-resistivity plume-like structure observed at KH1 site is caused by an intense clay alteration (mostly smectite), hence interface conduction, as well as interfoliar conduction within smectite crystals, whose high electrical conductivity is enhanced by high temperature. A strong temperature-dependence of interface conduction has been observed by Nono et al. (2018) on cores from Nesjavellir and Reykjanes, two high-temperature areas in Iceland, with a change of conductivity of one order of magnitude between 0 and $100^{\circ} \mathrm{C}$. A temperature-dependence of smectite interfoliar conduction can also be expected since an increase of temperature would enhance the mobility of cations (charge carriers) throughout connected interfoliar spaces of smectite crystals. Laboratory measurements on single-crystal vermiculite confirm that interfoliar conduction increases with temperature (Maraqah et al. 1990).

The field MPA are lower than the laboratory MPA, even after the frequency-range difference has been accounted for (Fig. 12). We briefly explore the possible effect of in-situ temperature on the MPA. The temperature-dependence of IP parameters is not well known, and especially not at these high temperatures (Treichel et al. 2014; Bairlein et al. 2016). We suggest in Appendix A a procedure to correct the phase-angle for the effect of temperature, which results in corrected laboratory MPA falling in the same range as field MPA for ISL-11, down to the DOI (Fig. 12). However, this comparison is only qualitative and the use of different correction coefficients could also work. The high MPA measured in the laboratory at depths between 120 and $150 \mathrm{~m}$ corresponds to layers below the DOI, so that the field MPA at these depths cannot be used for comparison to laboratory MPA. 
Table 2. Summary of the ERT and IP signatures of the three sites investigated and comparison to known mineralogy and hydrothermal activity.

\begin{tabular}{llll}
\hline & \multicolumn{1}{c}{ KH3 } & \multicolumn{1}{c}{ KH1 } & \multicolumn{1}{c}{ KS1 } \\
\hline ERT & Conductive layer & Conductive plume & Overall resistive \\
IP & (IP signal too noisy) & High MPA with long relaxation time. & High MPA with short relaxation time \\
Mineralogy & Altered hyaloclastite (smectite and & $\begin{array}{l}\text { Overall very altered, evidences of } \\
\text { boiling, smectite and pyrite abundant }\end{array}$ & Fresh basalt, iron-oxides abundant \\
Activity & $\begin{array}{l}\text { little pyrite) } \\
\text { Cold, possible former regional } \\
\text { circulation }\end{array}$ & & Cold at shallow depth \\
& & & \\
\hline
\end{tabular}

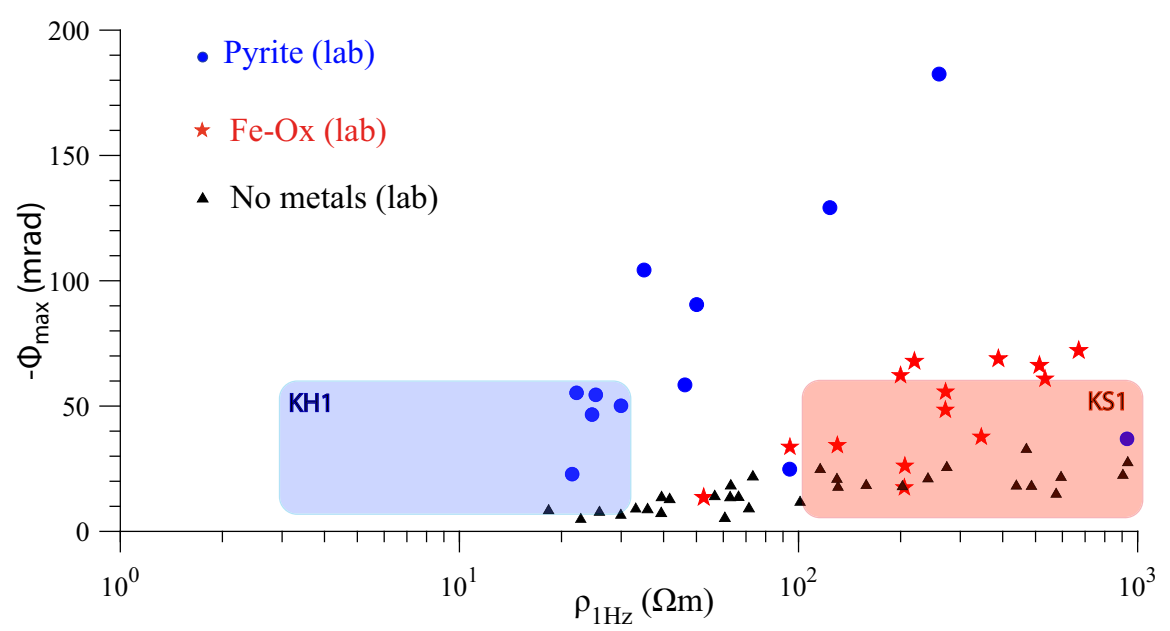

Figure 16. MPA versus DC resistivity from laboratory measurements on core samples and from inversion of field data. Laboratory measurements at room temperature are carried out on samples from boreholes $\mathrm{KH} 1$ and $\mathrm{KH} 3$ as well as two other boreholes in the western side of the Krafla caldera (KH5 and KH6). The laboratory DC resistivity is approximated by the resistivity measured at $1 \mathrm{~Hz}$. The blue circles and red stars correspond to pyrite-rich and magnetite-rich samples, respectively, while the black triangles correspond to samples with less than 1 per cent metallic particles. The blue and red rectangles show the ranges of MPA and DC resistivity resulting from inversions at KH1 and KS1 site, respectively.

There is also a possible effect of temperature on the relaxation time since $\tau$ is sensitive to fluid conductivity (e.g. Gurin et al. 2015). However, the relaxation time values obtained from the inversion cannot be quantitatively compared to the relaxation time obtained in the laboratory, in particular due to the limited time-range investigated in the field.

\subsection{Influence of smectite on IP data quality (KH1 and KH3)}

Field data at $\mathrm{KH} 3$ and $\mathrm{KH} 1$ sites are characterized by noisy voltage discharge curves, which cannot be included in the inversion input data.

At KH3, noisy voltage discharge curves are systematically associated with low apparent resistivity, whereas clean IP decays are associated with high apparent resistivity (Fig. 4). The near-horizontal low-resistivity body, observed on the ERT inversions of all profiles at $\mathrm{KH} 3$, is interpreted as a smectite-rich layer, based on comparison to borehole logs and laboratory analyses.

At KH1, a cylindrical low-resistivity body is observed and attributed to an up-flow causing extensive hydrothermal alteration, with in particular abundant formation of smectite. Noisy voltage discharge curves are associated to this central low-resistivity body at profiles ISL-10 and ISL-11, and to some extent ISL-12. Yet, the spatial distribution of the smectite-rich body does not obstruct the IP measurements as much as at $\mathrm{KH} 3$ site. The resistive structures on the sides of the profiles at KH1 site allow resolving IP parameters in these zones and thus in parts of the central zone, thanks to lateral constraints in the inversion. On the other hand, at KH3 site, the low-resistivity layer completely screens the IP signal.

These observations suggest that an abundance of smectite, especially as a thick layer, is a major obstacle to retrieve good IP data quality in volcanic environments. The conductive properties of smectite, especially the diffusion of ions through interfoliar spaces, might prevent the creation of high voltages in the ground (Lévy et al. 2018, 2019), which are a prerequisite for good quality IP data (Gazoty et al. 2013). More generally, low or even negative apparent chargeability have been observed over conductive and polarizable bodies and interpreted as the effect of conduction, preventing relaxation (Sumner 1976). This emphasizes the importance of fitting the voltage discharge curves with IP decays to ensure that discharge curves contain information about the electrical charge storage capabilities of the rock and not about other sources of polarization (e.g. cross-talking between cables or spontaneous polarization).

The creation of larger voltage in smectite-rich environments would require injection of larger currents. Instruments including independent dipoles for injection and potential measurements could be adapted for this purpose. Induction-based soundings, such as Transient Electromagnetic (TEM), could also be a solution to obtain a deeper IP signal in conductive environments. Yet, a strong IP anomaly needs to be present in the ground to be imaged by TEM soundings, especially if the host rock is conductive (Flis et al. 1989). 


\subsection{Interest of shallow ERT/TDIP investigations for geothermal exploration}

The very different resistivity signatures of KH1 and KS1 sites at shallow depths illustrate the spatial variability of lithological and tectonic features, which can exist along caldera boundaries over short distances (see Table 2 for a summary of these different features). ERT measurements allow identifying shallow structures relevant for geothermal exploration, such as localized up-flow zones, and thus bring complementary information to electromagnetic soundings, which are usually inverted in a larger grid and overlook these shallow localized structures.

IP measurements bring more details about the mineralogy at shallow depth, compared to structures imaged by DC resistivity only. Our study shows that pyrite and iron-oxides can be identified with DCIP soundings in volcanic environments. However, the presence of clay minerals such as smectite is difficult to detect with IP soundings, due to high electrical conduction associated with smectite alteration in these environments, concurring with polarization. The best IP signal is obtained in resistive zones, which can either correspond to fresh unaltered basalt or to altered basalt without smectite, for example, when smectite has been replaced by chlorite. This last case was not observed in our study.

Although the depth range investigated is large compared to many IP campaigns, it remains small compared to common target depths of interest for geothermal targets (more than $1 \mathrm{~km}$ ). A joint analysis of TEM and ERT/TDIP (with higher injected current) could possibly allow obtaining the IP signal down to $1 \mathrm{~km}$ depth.

\section{CONCLUSIONS}

Here, we have used the eastern Krafla caldera boundary as a laboratory to better understand the spatial variations in lithology, mineralogy and volcanotectonic structures, which can be expected over short distances at caldera boundaries. ERT at an active volcano (Krafla, Iceland) has highlighted an up-flow zone of cylindrical shape, located at the intersection of two tectonic features: the southern caldera rim and NNE-SSW faults associated with the main rifting axis. This shallow low-resistivity anomaly was not detected in previous electromagnetic soundings, conventionally used for geothermal exploration. TDIP has allowed identifying a region with high MPA and long relaxation time associated with this lowresistivity anomaly, which was interpreted as pyrite-rich. TDIP measurements appear to be useful to detect and discriminate pyrite and iron-oxides but seem to be rather not sensitive to the presence of smectite. Our results confirm that the abundance of smectite, a clay mineral common at shallow depths in volcanic environments, leads to high conduction and low polarization. The abundance of smectite appears to be an obstacle to the transformation of injected currents into high voltage and thus to the retrieval of good quality IP data. The naturally-high conductivity of smectite is enhanced by high temperatures: at the hot site, the temperature difference between in-situ and laboratory resistivity measurements corresponds to an overall increase of the electrical conductivity of 6 per cent per ${ }^{\circ} \mathrm{C}$. The inverted MPA from time-domain field measurements at the hot site are consistent with laboratory frequency-domain measurements on borehole samples from this site, down to the depth of investigation of about $120 \mathrm{~m}$, provided that the frequency-range where the laboratory MPA is retrieved is reduced to approximately match the time-range investigated in the field. A decrease of MPA with temperature is also possible. At the cold altered site, resistivity from laboratory measurements, borehole logs and inversion of field data are consistent but the IP data could not be inverted, due to a nearhorizontal smectite-rich conductive layer affecting the quality of IP data. At the cold unaltered site (the most resistive of the three sites), the best IP signal was obtained and a high MPA associated with short relaxation time was attributed to the presence of iron-oxides.

\section{ACKNOWLEDGEMENTS}

Editor Alexis Maineult and reviewers Tina Martin and Konstantyn Titov are thanked for improving the clarity and scientific quality of the manuscript, through an efficient review process. The power company Landsvirkjun is thanked for providing with on-site accommodation and facilities during the field campaign. Anthony Finizola, Renaud Trinquier and Anna Kristín Árnadóttir are thanked for helping with material transportation issues. André Revil, Sveinbjorn Steinthórsson, Daniel Juncu and Vincent Drouin are thanked for their help in the field, and Stefán Auðunn Stefánsson for the logistical support. Volker Rath is thanked for constructive discussion. LL thanks Gylfi Páll Hersir for his constructive comments on the manuscript and his general support and Lee Slater for valuable feedbacks and discussions on the manuscript. LL also thanks Pierre Briole and Ólafur G. Flóvenz for their support with the organisation of the field campaign. The company Jarðboranir is thanked for providing bentonite for field measurements. The company Aarhus GeoSoftware is thanked for providing a free trial license for Aarhus Workbench to LL. 3-D figures were made with the freeware Paraview. This work was supported by a PhD grant from Paris Sciences et Lettres to Léa Lévy and the IMAGE FP7 EC and GEMex H2020 projects (grant agreements 608553 and 727550). Fundings for the field measurements were provided by the French Ministries of Foreign Affairs and International Development and of Education, Teaching and Research, through the PHC program Jules Verne, granted to Ecole Normale Supérieure and University of Iceland, as well as by a CNRS-INSU grant to University of Savoie-Mont Blanc. Equipment transportation expenses were covered by University of Montpellier and also supported by University of La Réunion.

\section{REFERENCES}

Abdulsamad, F., Florsch, N. \& Camerlynck, C., 2017. Spectral induced polarization in a sandy medium containing semiconductor materials: experimental results and numerical modelling of the polarization mechanism, Near Surf. Geophys., 15(6), 669-683.

Archie, G.E., 1942. The electrical resistivity $\log$ as an aid in determining some reservoir characteristics, Trans. AIME, 146(01), 54-62.

Ármannsson, H., Gudmundsson, A. \& Steingrímsson, B.S., 1987. Exploration and development of the Krafla geothermal area, Jökull, 37, 13-30.

Árnason, K. \& Magnússon, I.T., 2001. Niðurstöður viðnámsmælinga í Kröflu (Results from electrical resistivity measurements at Krafla), Report OS-2001/062, Orkustofnun (in Icelandic).

Árnason, K., Vilhjálmsson, A. \& Björnsdóttir, T., 2007. A Study of the Krafla Volcano using Gravity, Micro Earthquake and MT Data, p. 14, KenGen.

Arps, J.J., 1953. The effect of temperature on the density and electrical resistivity of sodium chloride solutions, J. Petrol. Tech., 5(10), 17-20.

Auken, E. et al., 2014. An overview of a highly versatile forward and stable inverse algorithm for airborne, ground-based and borehole electromagnetic and electric data, Explor. Geophys., 46(3), 223-235.

Bairlein, K., Bücker, M., Hördt, A. \& Hinze, B., 2016. Temperature dependence of spectral induced polarization data: experimental results and membrane polarization theory, Geophys. J. Int., 205(1), 440-453.

Beaufort, D., Papapanagiotou, P., Patrier, P., Fujimoto, K. \& Kasai, K., 1995. High-temperature smectites in active geothermal systems, in Proceedings 8th Water-Rock Interaction Symposium, Vladivostok, Balkema, Rotterdam, pp. 1071-1076. 
Bertin, J. \& Loeb, J., 1976. Experimental and Theoretical Aspects of Induced Polarization, Vol. 1, Schweizerbart Science Publishers.

Bücker, M., Flores Orozco, A. \& Kemna, A., 2018. Electro-chemical polarization around metallic particles-part 1: the role of diffuse-layer and volume-diffusion relaxation, Geophysics, 83(4), 1-53.

Dahlin, T. \& Leroux, V., 2012. Improvement in time-domain induced polarization data quality with multi-electrode systems by separating current and potential cables, Near Surf. Geophys., 10(6), 545-565.

Dahlin, T. \& Zhou, B., 2006. Multiple-gradient array measurements for multichannel 2d resistivity imaging, Near Surf. Geophys., 4(2), 113-123.

Edwards, L.S., 1977. A modified pseudosection for resistivity and IP, Geophysics, 42(5), 1020-1036.

Fiandaca, G., 2018. Induction-free acquisition range in spectral time- and frequency-domain induced polarization at field scale, Geophys. J. Int., doi:10.1093/gji/ggy409.

Fiandaca, G., Auken, E., Christiansen, A.V. \& Gazoty, A., 2012. Timedomain-induced polarization: full-decay forward modeling and 1d laterally constrained inversion of cole-cole parameters, Geophysics, 77(3), E213-E225.

Fiandaca, G., Ramm, J., Binley, A., Gazoty, A., Christiansen, A.V. \& Auken, E., 2013. Resolving spectral information from time domain induced polarization data through 2-d inversion, Geophys. J. Int, 192, 631-646.

Fiandaca, G., Christiansen, A.V. \& Auken, E., 2015. Depth of investigation for multi-parameters inversions, in, Near Surface Geoscience 2015-21st European Meeting of Environmental and Engineering Geophysics (Extended Abstract), Turin, Italy, doi:10.3997/2214-4609.201413797.

Fiandaca, G., Madsen, L.M. \& Maurya, P.K., 2018. Re-parameterisations of the cole-cole model for improved spectral inversion of induced polarization data, Near Surf. Geophys., 16(4), 385-399.

Flis, M.F., Newman, G.A. \& Hohmann, G.W., 1989. Induced-polarization effects in time-domain electromagnetic measurements, Geophysics, 54(4), $514-523$.

Flores Orozco, A., Kemna, A., Oberdörster, C., Zschornack, L., Leven, C., Dietrich, P. \& Weiss, H., 2012. Delineation of subsurface hydrocarbon contamination at a former hydrogenation plant using spectral induced polarization imaging, J. Contaminant Hydrol., 136, 131-144.

Flores Orozco, A., Bücker, M., Steiner, M. \& Malet, J.-P., 2018. Complexconductivity imaging for the understanding of landslide architecture, Eng. Geol., 243, 241-252.

Flóvenz, O., Georgsson, L. \& Árnason, K., 1985. Resistivity structure of the upper crust in iceland, J. geophys. Res., 90(B12), 10 136-10 150.

Flóvenz, O.G., Spangenberg, E., Kulenkampf, J., Árnason, K., Karlsdóttir, R. \& Huenges, E., 2005. The role of electrical interface conduction in geothermal exploration, in Proceedings of World Geothermal Congress 2005, International Geothermal Association.

Gasperikova, E., Newman, G., Feucht, D. \& Árnason, K., 2011. 3D MT characterization of two geothermal fields in Iceland, GRC Trans., 35, $1667-1671$.

Gazoty, A., Fiandaca, G., Pedersen, J., Auken, E. \& Christiansen, A.V., 2013. Data repeatability and acquisition techniques for time-domain spectral induced polarization, Near Surf. Geophys., 11(4), 391-406.

Ghorbani, A., Revil, A., Coperey, A., Ahmed, A.S., Roque, S., Heap, M., Grandis, H. \& Viveiros, F., 2018. Complex conductivity of volcanic rocks and the geophysical mapping of alteration in volcanoes, J. Volc. Geotherm. Res., 357, 106-127.

Gresse, M. et al., 2017. 3-D resistivity tomography of the Solfatara crater (Italy): implication for the multiphase flow structure of the shallow hydrothermal system, J. geophys. Res., 122(11), 8749-8768.

Gudmundsson, A., 1991. Borun kjarnaholu i Sandabotnaskarð(Drilling of cored hole in Sandabotnaskard), Unpublished report in Icelandic, Orkustofnun.

Gudmundsson, A., Egilson, T. \& Haraldson, K., 2007. Krafla - Hola KS-01. Forborun og 1. áfangi. (Hole KS-01 at Krafla: pre-drilling and first phase), Report in Icelandic LV-2007/055, Landsvirkjun.

Gudmundsson, A., Mortensen, A.K., Hjartarson, A., Karlsdóttir, R. \& Ármannsson, H., 2010. Exploration and utilization of the Namafjall high temperature area in North Iceland, in Proceedings of World Geothermal Congress 2010, Bali, Indonesia.
Gurin, G., Titov, K., Ilyin, Y. \& Tarasov, A., 2015. Induced polarization of disseminated electronically conductive minerals: a semi-empirical model, Geophys. J. Int., 200(3), 1555-1565.

Gurin, G., Ilyin, Y., Nilov, S., Ivanov, D., Kozlov, E. \& Titov, K., 2018. Induced polarization of rocks containing pyrite: interpretation based on x-ray computed tomography, J. appl. Geophys., 154, 50-63.

Helander, D.P., 1983. Fundamentals of formation evaluation, Oil \& Gas Consultants Intl., ISBN:978-0930972028.

Hjartardóttir, Á., Einarsson, P., Magnúsdóttir, S., Björnsdóttir, P. \& Brandsdóttir, B., 2016. Fracture systems of the northern volcanic rift zone, , Iceland: An Onshore Part of the Mid-Atlantic Plate Boundary, Vol. 1, pp. 297-314, Geological Society, London, Special Publications.

Hjartardóttir, Á.R., Einarsson, P., Bramham, E. \& Wright, T.J., 2012. The Krafla fissure swarm, iceland, and its formation by rifting events, Bull. Volcanol., 74(9), 2139-2153.

Hupfer, S., Martin, T., Weller, A., Günther, T., Kuhn, K., Ngninjio, V.D.N. \& Noell, U., 2016. Polarization effects of unconsolidated sulphide-sandmixtures, J. appl. Geophys., 135, 456-465.

Ingeman-Nielsen, T. \& Baumgartner, F., 2006. Numerical modelling of complex resistivity effects on a homogenous half-space at low frequencies, Geophys. Prospect., 54(3), 261-271.

Johansen, H., 1977. A man/computer interpretation system for resistivity soundings over a horizontally strafified earth, Geophys. Prospect., 25(4), 667-691.

Jónasson, K., 1994. Rhyolite volcanism in the Krafla central volcano, northeast iceland, Bull. Volcanol., 56(6-7), 516-528.

Jónsson, S.S., Gudmundsson, A. \& Thordarson, S., 2003. Krafla borun kjarnaholu KH3 milli Jörundar og Háganga (Drilling of cored hole KH3 at Krafla, between Jörundur and Hágöng), Report in Icelandic ÍSOR2003/015, ÍSOR.

Kemna, A. et al., 2012. An overview of the spectral induced polarization method for near-surface applications, Near Surf. Geophys., 10(6), 453468.

Kristinsdóttir, L.H., Flóvenz, O.G., Árnason, K., Bruhn, D., Milsch, H., Spangenberg, E. \& Kulenkampff, J., 2010. Electrical conductivity and pwave velocity in rock samples from high-temperature icelandic geothermal fields, Geothermics, 39(1), 94-105.

Leroy, P., Weigand, M., Mériguet, G., Zimmermann, E., Tournassat, C., Fagerlund, F., Kemna, A. \& Huisman, J.A., 2017. Spectral induced polarization of na-montmorillonite dispersions, J. Colloid Interf. Sci., 505, 1093-1110.

Lesmes, D.P. \& Frye, K.M., 2001. Influence of pore fluid chemistry on the complex conductivity and induced polarization responses of Berea sandstone, J. geophys. Res., 106(B3), 4079-4090.

Lévy, L., Gibert, B., Sigmundsson, F., Flóvenz, O.G., Hersir, G.P., Briole, P. \& Pezard, P.A., 2018. The role of smectites in the electrical conductivity of active hydrothermal systems: electrical properties of core samples from Krafla volcano, Iceland, Geophys. J. Int., 215(3), $1558-1582$.

Lévy, L., Gibert, B., Sigmundsson, F., Parat, F., Deldicque, D. \& Hersir, G.P., 2019. Tracking magmatic hydrogen sulphur circulations using electrical impedance : complex electrical properties of core samples at the Krafla volcano, Iceland, J. geophys. Res., 124(3), 2492-2509.

Libbey, R.B. \& Williams-Jones, A.E., 2013. Sulfide mineralization in the Reykjanes geothermal system, Iceland; potential applications for geothermal exploration, GRC Trans., 37, 417-424.

Loke, M.H., 2004. Tutorial: 2-D and 3-D electrical imaging surveys, set of notes. Available at: https://www.researchgate.net/profile/Meng_Loke/pu blication/264739285_Tutorial_2-D_and_3-D_Electrical_Imaging_Surve ys, Last Access 1 June 2019.

Loke, M.H. \& Barker, R., 1996. Rapid least-squares inversion of apparent resistivity pseudosections by a quasi-Newton method 1, Geophys. Prospect., 44(1), 131-152.

Madsen, L.M., Fiandaca, G., Auken, E. \& Christiansen, A.V., 2017. Timedomain induced polarization-an analysis of cole-cole parameter resolution and correlation using Markov chain Monte Carlo inversion, Geophys. J. Int., 211(3), 1341-1353. 
Maraqah, H., Li, J. \& Whittingham, M.S., 1990. Ion transport in single crystals of the clay-like aluminosilicate, vermiculite, in MRS Online Proceedings Library Archive, Vol. 210, p. 351, Materials Research Society.

Maurya, P.K., Fiandaca, G., Christiansen, A.V. \& Auken, E., 2018. Fieldscale comparison of frequency-and time-domain spectral induced polarization, Geophys. J. Int., 214(2), 1441-1466.

Menke, W., 2012. Chapter 9 - Nonlinear inverse problems, in Geophysical Data Analysis: Discrete Inverse Theory, 3rd edn pp. 163-188, ed. Menke, W., Academic Press.

Meunier, A., 2005. Clays, Springer Science \& Business Media.

Misra, S., Torres-Verdín, C., Revil, A., Rasmus, J. \& Homan, D., 2016. Interfacial polarization of disseminated conductive minerals in absence of redox-active species-part 1: Mechanistic model and validation, Geophysics, 81(2), E139-E157.

Nono, F., Gibert, B., Parat, F., Loggia, D., Cichy, S.B. \& Violay, M., 2018. Electrical conductivity of Icelandic deep geothermal reservoirs up to supercritical conditions: insight from laboratory experiments, J. Volc. Geotherm. Res., doi:10.1016/j.jvolgeores.2018.04.021.

Olsson, P.-I., Fiandaca, G., Dahlin, T. \& Auken, E., 2015. Impact of time-domain IP pulse length on measured data and inverted models, in Near Surface Geoscience 2015-21st European Meeting of Environmental and Engineering Geophysics (Extended Abstract), doi:10.3997/22144609.201413755, Turin, Italy.

Olsson, P.-I., Fiandaca, G., Larsen, J.J., Dahlin, T. \& Auken, E., 2016. Doubling the spectrum of time-domain induced polarization by harmonic de-noising, drift correction, spike removal, tapered gating and data uncertainty estimation, Geophys. J. Int., 207(2), 774-784.

Parkhomenko, E.I., 1971. Electrification Phenomena in Rocks, Springer Science \& Business Media New York.

Patrier, P., Papapanagiotou, P., Beaufort, D., Traineau, H., Bril, H. \& Rojas, J., 1996. Role of permeability versus temperature in the distribution of the fine $(\leq 0.2 \mu \mathrm{m})$ clay fraction in the Chipilapa geothermal system (El Salvador, Central America), J. Volc. Geotherm. Res., 72(1), 101-120.

Pelton, W.H., Ward, S.H., Hallof, P.G., Sill, W.R. \& Nelson, P.H., 1978. Mineral discrimination and removal of inductive coupling with multifrequency IP, Geophysics, 43(3), 588-609.

Revil, A., Florsch, N. \& Mao, D., 2015. Induced polarization response of porous media with metallic particles - Part 1: a theory for disseminated semiconductors, Geophysics, 80(5), 525-538.

Revil, A., Le Breton, M., Niu, Q., Wallin, E., Haskins, E. \& Thomas, D.M., 2017a. Induced polarization of volcanic rocks. Part 1: Surface versus quadrature conductivity, Geophys. J. Int., 208(2), 826-844.

Revil, A., Murugesu, M., Prasad, M. \& Le Breton, M., 2017b. Alteration of volcanic rocks: A new non-intrusive indicator based on induced polarization measurements, J. Volc. Geotherm. Res., 341, 351-362.

Rosenkjaer, G.K., Gasperikova, E., Newman, G.A., Árnason, K. \& Lindsey, N.J., 2015. Comparison of 3D MT inversions for geothermal exploration: case studies for Krafla and Hengill geothermal systems in Iceland., Geothermics, 57, 258-274.

Sæmundsson, K., 1991. Náttúra Mývatns (Nature at Mývatn's area), chap. Jarðfrce $i$ Kröflukerfisins (Geology of the Krafla volcanic system), pp. 25-95, Hið íslenska náttúrufræðifélag, Reykjavík, Book in Icelandic.

Sæmundsson, K., 2015. Catalogue of Icelandic volcanoes - Krafla, in Icelandic Volcanoes. Available at: http://www.icelandicvolcanos.is/?volcan $\mathrm{o}=\mathrm{KRA}$, last access 1 June 2019.

Sæmundsson, K., Pringle, M.S. \& Hardarson, B.S., 2000. About the age of strata in the Krafla volcanic system, in Proceedings of the Geoscience Society of Iceland, Spring Meeting, pp. 26-27, Reykjavík.

Saemundsson, K., Hjartarson, A., Kaldal, I., Sigurgeirsson, M.A., Kristinsson, S.G. \& Víkingsson, S., 2012. Geological map of the northern volcanic zone, Iceland. Northern part 1:100 000, Reykjavík: Iceland Geosurvey and Landsvirkjun.

Scott, J.H., 1984. Computer Analysis of Digital Well Logs, US Department of the Interior, Geological Survey Circular 879.

Sigmarsson, O. \& Steinthórsson, S., 2007. Origin of icelandic basalts: a review of their petrology and geochemistry, J. Geodyn., 43(1), 87-100.

Sigmundsson, F., 2006. Iceland Geodynamics: Crustal Deformation and Divergent Plate Tectonics, Springer Science \& Business Media.
Slater, L.D. \& Sandberg, S.K., 2000. Resistivity and induced polarization monitoring of salt transport under natural hydraulic gradients, Geophysics, 65(2), 408-420.

Sumner, J.S., 1976. Principles of induced polarization for geophysical exploration, in Developments in Economic Geology, 5, Elsevier Scientific Publishing Company.

Telford, W.M., Geldart, L.P. \& Sheriff, R.E., 1990. Applied Geophysics, 2nd edn, Cambridge University Press.

Treichel, A., Binley, A., Kemna, A., Esser, O., Zimmermann, E., Vereecken, H. \& Huismann, J., 2014. Temperature dependence of broadband complex electrical conductivity in unconsolidated porous media with variable clay content, in Proceedings of the 3rd International Workshop on Induced Polarization, pp. 38-39, Ile d'Oleron France.

Tuffen, H. \& Castro, J.M., 2009. The emplacement of an obsidian dyke through thin ice: Hrafntinnuhryggur, Krafla Iceland, J. Volc. Geotherm. Res., 185(4), 352-366.

Vinegar, H. \& Waxman, M., 1984. Induced polarization of shaly sands, Geophysics, 49(8), 1267-1287.

Wait, J.R., 1987. Physical model for the complex resistivity of the earth, Electron. Lett., 23(19), 979-980.

Waxman, M.H. \& Smits, L.J.M., 1968. Electrical conductivities in oilbearing shaly sands, Soc. Pet. Eng. J., 8, 107-122.

Weller, A., Slater, L. \& Nordsiek, S., 2013. On the relationship between induced polarization and surface conductivity: Implications for petrophysical interpretation of electrical measurements, Geophysics, 78(5), D315-D325.

Wong, J., 1979. An electrochemical model of the induced-polarization phenomenon in disseminated sulfide ores, Geophysics, 44(7), 1245-1265.

\section{SUPPORTING INFORMATION}

Supplementary data are available at $\langle 0$ :italic $\rangle \mathrm{GJI}\langle/ 0$ :italic $\rangle$ online.

Figure S1. Phase-angle measured spectra versus theoretical predictions for three networks of resistors and capacitors of known impedance. A deviation of $0.5 \mathrm{mrad}$ is observed between measurements and predictions.

Figure S2. Phase-angle spectra measured with the electrical cell filled with water at different salinities. Deviations of $1 \mathrm{mrad}$, compared to the supposed absence of polarization response of pure water below $1 \mathrm{kHz}$, are observed.

Figure S3. Apparent chargeability (decay voltage normalized by the primary voltage) as a function of time, measured during the off-time for one quadrupole of electrodes, corresponding to the positions $\mathrm{AMNB}=0-40-80-560$. The four different colours correspond to four different sets of measurements: three different current injection times and one reciprocal measurements for the $0.4 \mathrm{~s}$ injection (inversion of current and potential cables). The reciprocal measurements are overlapping.

Figure S4. DCIP inversion (resistivity, chargeability and normalized chargeability) for profile ISL-11 (KH1 site), using the 'Resistivity Cole-Cole' (RCC) parametrization, instead of the 'Maximum Phase Angle' parametrization used in the rest of the study. This RCC parametrization allows us to calculate the normalized chargeability. Figure S5. Resistivity inversion for profiles ISL-6 and ISL-8. The upper panels are the inversion models, showing two white lines in the lower part of the figure for the shallow and deep DOI. The middle panels are the apparent resistivity pseudo-sections. The lower panels give the data misfit $\chi$ for each vertical section of model (spaced every $40 \mathrm{~m})$.

Figure S6. MPA versus relaxation time based on frequency-domain laboratory measurements on core samples. The range of relaxation time that can be resolved with TDIP field measurements is shown in grey. 
Figure S7. Grain size distribution of metallic particles for the six samples whose phase spectrum are represented in the main text (pyrite for L2, L6, L9, L119 and L123 and magnetite for L117). These distributions are calculated based on image analyses presented by Lévy et al. (2019).

Figure S8. Simplified lithological log in borehole KH1, adapted from Gudmundsson (1991). The lengths of the various lithological layers are made different for clarity purposes, so that very thin layers are not confused with boundaries between layers.

Figure S9. Resistivity inversion model for ISL-13 (perpendicular profile at KH1 site). The data and forward prediction of the model are also shown. The lower panels give the data misfit $\chi$ for each vertical section of model (spaced every $40 \mathrm{~m}$ ).

Please note: Oxford University Press is not responsible for the content or functionality of any supporting materials supplied by the authors. Any queries (other than missing material) should be directed to the corresponding author for the paper.

\section{APPENDIX A: SAMPLES USED FOR COMPARISON TO FIELD DATA}

Table A1. Main characteristics of the 38 samples used for comparison to field data. BH= borehole. Columns 4 to 7 give the measured conductivity at different pore fluid conductivities, in $\mathrm{S} \mathrm{m}^{-1}$.

\begin{tabular}{|c|c|c|c|c|c|c|c|}
\hline Sample & $\mathrm{BH}$ & Depth (m) & $\sigma_{0.02 S / m}$ & $\sigma_{0.05 S / m}$ & $\sigma_{0.1 S / m}$ & $\sigma_{0.5 S / m}$ & Lithology \\
\hline L12a & KH1 & 70 & $1.39 \mathrm{E}-03$ & $1.49 \mathrm{E}-03$ & $1.62 \mathrm{E}-03$ & $2.30 \mathrm{E}-03$ & Dense lava \\
\hline L12b & KH1 & 70 & $1.82 \mathrm{E}-03$ & $1.95 \mathrm{E}-03$ & $2.11 \mathrm{E}-03$ & $3.30 \mathrm{E}-03$ & Dense lava \\
\hline F58 & KH1 & 187.5 & $2.06 \mathrm{E}-03$ & $1.96 \mathrm{E}-03$ & $2.41 \mathrm{E}-03$ & $3.30 \mathrm{E}-03$ & Dyke \\
\hline $\mathrm{L} 5 \mathrm{~b}$ & KH1 & 45.3 & $2.59 \mathrm{E}-03$ & $2.86 \mathrm{E}-03$ & $2.93 \mathrm{E}-03$ & $4.24 \mathrm{E}-03$ & Ignimbrite \\
\hline L30 & KH1 & 185.1 & $4.13 \mathrm{E}-03$ & $4.87 \mathrm{E}-03$ & $4.91 \mathrm{E}-03$ & $6.01 \mathrm{E}-03$ & Dyke \\
\hline L19 & KH1 & 120.3 & $7.11 \mathrm{E}-03$ & $8.08 \mathrm{E}-03$ & $9.13 \mathrm{E}-03$ & $1.41 \mathrm{E}-02$ & Dense basalt \\
\hline L5a & KH1 & 45.3 & $7.61 \mathrm{E}-03$ & $8.76 \mathrm{E}-03$ & $9.27 \mathrm{E}-03$ & $1.41 \mathrm{E}-02$ & Ignimbrite \\
\hline L26 & KH1 & 157.9 & $8.53 \mathrm{E}-03$ & $1.06 \mathrm{E}-02$ & $1.11 \mathrm{E}-02$ & $1.43 \mathrm{E}-02$ & Lava layer \\
\hline L28 & KH1 & 167.1 & $8.89 \mathrm{E}-03$ & $1.06 \mathrm{E}-02$ & $1.09 \mathrm{E}-02$ & $1.26 \mathrm{E}-02$ & Dense basalt \\
\hline L29 & KH1 & 174.3 & $1.14 \mathrm{E}-02$ & $1.36 \mathrm{E}-02$ & $1.49 \mathrm{E}-02$ & $1.98 \mathrm{E}-02$ & Lava layer \\
\hline L15 & KH1 & 79.5 & $1.29 \mathrm{E}-02$ & $1.58 \mathrm{E}-02$ & $1.54 \mathrm{E}-02$ & $1.95 \mathrm{E}-02$ & Lava layer \\
\hline L16 & KH1 & 99 & $1.44 \mathrm{E}-02$ & $1.59 \mathrm{E}-02$ & $1.55 \mathrm{E}-02$ & $1.90 \mathrm{E}-02$ & Lava layer \\
\hline L21 & KH1 & 125.5 & $1.50 \mathrm{E}-02$ & $1.90 \mathrm{E}-02$ & $1.96 \mathrm{E}-02$ & $2.37 \mathrm{E}-02$ & Lava layer \\
\hline L6 & KH1 & 48.8 & $1.51 \mathrm{E}-02$ & $2.00 \mathrm{E}-02$ & $1.73 \mathrm{E}-02$ & $3.12 \mathrm{E}-02$ & Welded breccia \\
\hline L2 & KH1 & 39.5 & $1.63 \mathrm{E}-02$ & $2.16 \mathrm{E}-02$ & $2.55 \mathrm{E}-02$ & $4.47 \mathrm{E}-02$ & Welded breccia \\
\hline L25 & KH1 & 151.3 & $1.67 \mathrm{E}-02$ & $2.85 \mathrm{E}-02$ & $3.28 \mathrm{E}-02$ & $5.23 \mathrm{E}-02$ & Dense altered basalt \\
\hline L11 & KH1 & 68.7 & $2.04 \mathrm{E}-02$ & $2.54 \mathrm{E}-02$ & $2.61 \mathrm{E}-02$ & $3.31 \mathrm{E}-02$ & Lava layer \\
\hline L10 & KH1 & 66 & $2.05 \mathrm{E}-02$ & $2.53 \mathrm{E}-02$ & $2.42 \mathrm{E}-02$ & $4.05 \mathrm{E}-02$ & Lava layer \\
\hline L14 & KH1 & 74.5 & $2.72 \mathrm{E}-02$ & $3.34 \mathrm{E}-02$ & $5.26 \mathrm{E}-02$ & $8.50 \mathrm{E}-02$ & Altered hyaloclastite \\
\hline L22 & KH1 & 131.1 & $2.88 \mathrm{E}-02$ & $3.96 \mathrm{E}-02$ & $4.30 \mathrm{E}-02$ & $5.19 \mathrm{E}-02$ & Lava layer \\
\hline L24b & KH1 & 144.1 & $3.01 \mathrm{E}-02$ & $4.06 \mathrm{E}-02$ & $4.20 \mathrm{E}-02$ & $5.52 \mathrm{E}-02$ & Altered hyaloclastite \\
\hline F61 & KH1 & 195 & $3.19 \mathrm{E}-02$ & $3.03 \mathrm{E}-02$ & $3.28 \mathrm{E}-02$ & $4.04 \mathrm{E}-02$ & Altered hyaloclastite \\
\hline L31 & KH1 & 188.5 & $3.23 \mathrm{E}-02$ & $3.86 \mathrm{E}-02$ & $4.83 \mathrm{E}-02$ & $6.16 \mathrm{E}-02$ & Altered hyaloclastite \\
\hline L24a & KH1 & 144.1 & $3.31 \mathrm{E}-02$ & $4.51 \mathrm{E}-02$ & $5.10 \mathrm{E}-02$ & $6.13 \mathrm{E}-02$ & Altered hyaloclastite \\
\hline L9 & KH1 & 60 & $3.89 \mathrm{E}-02$ & $4.65 \mathrm{E}-02$ & $5.25 \mathrm{E}-02$ & $6.38 \mathrm{E}-02$ & Altered hyaloclastite \\
\hline L116 & KH3 & 41.75 & $2.82 \mathrm{E}-03$ & $2.89 \mathrm{E}-03$ & $3.16 \mathrm{E}-03$ & $4.62 \mathrm{E}-03$ & Dense and fresh basalt \\
\hline L117 & KH3 & 47.8 & $1.91 \mathrm{E}-03$ & - & $2.22 \mathrm{E}-03$ & $3.19 \mathrm{E}-03$ & Dense and fresh basalt \\
\hline L118 & KH3 & 54.25 & $1.96 \mathrm{E}-03$ & - & $2.44 \mathrm{E}-03$ & $3.32 \mathrm{E}-03$ & Dense and fresh basalt \\
\hline L119 & KH3 & 60.4 & $3.12 \mathrm{E}-02$ & $3.34 \mathrm{E}-02$ & $4.00 \mathrm{E}-02$ & $5.58 \mathrm{E}-02$ & Altered hyaloclastite \\
\hline L120 & KH3 & 70.8 & $1.35 \mathrm{E}-02$ & $1.50 \mathrm{E}-02$ & $1.95 \mathrm{E}-02$ & $3.49 \mathrm{E}-02$ & Altered hyaloclastite \\
\hline L121 & KH3 & 72.7 & $2.40 \mathrm{E}-02$ & $2.79 \mathrm{E}-02$ & $3.80 \mathrm{E}-02$ & $6.21 \mathrm{E}-02$ & Altered hyaloclastite \\
\hline L122 & KH3 & 83.1 & $2.00 \mathrm{E}-02$ & $2.40 \mathrm{E}-02$ & $3.17 \mathrm{E}-02$ & $5.83 \mathrm{E}-02$ & Altered hyaloclastite \\
\hline L123 & KH3 & 91.8 & - & $5.46 \mathrm{E}-02$ & $7.99 \mathrm{E}-02$ & $1.25 \mathrm{E}-01$ & Altered hyaloclastite \\
\hline L157 & KH3 & 100 & - & $1.41 \mathrm{E}-02$ & - & - & Basaltic breccia \\
\hline L158 & KH3 & 114 & - & $8.93 \mathrm{E}-03$ & - & - & Basaltic breccia \\
\hline L35 & KH3 & 151.2 & $9.59 \mathrm{E}-03$ & $1.33 \mathrm{E}-02$ & $1.54 \mathrm{E}-02$ & $1.93 \mathrm{E}-02$ & Basaltic tuff \\
\hline L36 & KH3 & 273.4 & $1.91 \mathrm{E}-03$ & $2.28 \mathrm{E}-03$ & $2.74 \mathrm{E}-03$ & $5.97 \mathrm{E}-03$ & Buried fine grained lava \\
\hline L37 & KH3 & 325.1 & $7.03 \mathrm{E}-03$ & $7.65 \mathrm{E}-03$ & $9.36 \mathrm{E}-03$ & $1.92 \mathrm{E}-02$ & Buried fine grained lava \\
\hline
\end{tabular}




\section{APPENDIX B: \\ TEMPERATURE-DEPENDENCE OF THE PHASE-ANGLE}

We build here an empirical equation to estimate the temperaturedependence of the phase-angle, assuming that in-phase and quadrature conductivity depend on temperature in a similar manner (eq. B1), following an Arps' relationship (Arps 1953).

$$
\begin{aligned}
& \frac{\rho^{\prime}\left(T_{0}\right)}{\rho^{\prime}(T)}=1+\alpha_{\rho^{\prime}}\left(T-T_{0}\right) \Longleftrightarrow \frac{\sigma^{\prime}(T)}{\sigma^{\prime}\left(T_{0}\right)}=1+\alpha_{\sigma^{\prime}}\left(T-T_{0}\right) \\
& \frac{\sigma^{\prime \prime}(T)}{\sigma^{\prime \prime}\left(T_{0}\right)}=1+\alpha_{\sigma^{\prime \prime}}\left(T-T_{0}\right)
\end{aligned}
$$

,where $\mathrm{T}$ and $T_{0}$ are the in-situ (from log) and reference temperature in ${ }^{\circ} \mathrm{C}$, respectively, $\sigma^{\prime}$ and $\sigma^{\prime \prime}$ are the in-phase and quadrature conductivity in $\mathrm{S} \mathrm{m}^{-1}$, respectively, $\alpha_{\sigma^{\prime}}$ and $\alpha_{\sigma^{\prime \prime}}$ are the correction coefficient for the in-phase and quadrature conductivity in ${ }^{\circ} \mathrm{C}^{-1}$, respectively, with $\alpha_{\sigma^{\prime}}=\alpha_{\rho^{\prime}}$.

Small phase angles ( $\phi \leq 200 \mathrm{mrad}$ in our measurements) can be approximated by the ratio between quadrature and in-phase conductivity. eq. (B2) presents the corresponding temperature-dependence for the phase-angle.

$\frac{\phi(T)}{\phi\left(T_{0}\right)}=\frac{\frac{\sigma^{\prime \prime}(T)}{\sigma^{\prime \prime}\left(T_{0}\right)}}{\frac{\sigma^{\prime}(T)}{\sigma^{\prime}\left(T_{0}\right)}}=\frac{1+\alpha_{\sigma^{\prime \prime}}\left(T-T_{0}\right)}{1+\alpha_{\sigma^{\prime}}\left(T-T_{0}\right)}$.

Using eq. (B1) and laboratory measurements of the quadrature conductivity at temperatures $25,50,75$ and $100{ }^{\circ} \mathrm{C}$ by Vinegar $\&$ Waxman (1984), we obtain the coefficients $\alpha_{\sigma^{\prime \prime}}=0.0282$ and $0.028^{\circ} \mathrm{C}^{-1}$ for a clay-rich sample and a sandstone sample. Using eq. (B1) as well and laboratory measurements of the quadrature conductivity of two volcanic samples heated up to $50^{\circ} \mathrm{C}$ by Ghorbani et al. (2018), we obtain a correction coefficient of $0.0213{ }^{\circ} \mathrm{C}^{-1}$. We consider that $\alpha_{\sigma^{\prime \prime}}=0.0282^{\circ} C^{-1}$ is the closest value to our conditions, given that it is fitted to measurements up to $100^{\circ} \mathrm{C}$ and corresponds to a clay-rich sample.

Then, we consider two distinct values for the temperaturedependence of the in-phase conductivity: $\alpha_{\sigma^{\prime}}=0.033^{\circ} \mathrm{C}^{-1}$, inferred from in-phase conductivity measurements by Vinegar \& Waxman
(1984), and $\alpha_{\sigma^{\prime}}=0.06^{\circ} \mathrm{C}^{-1}$, fitted to our results and consistent with other studies on Icelandic volcanic samples, as mentioned earlier.

Samples from KH1 analysed here were extracted from depths corresponding to the temperature range $75-165^{\circ} \mathrm{C}$. In this range of temperatures and considering the coefficients $\alpha_{\sigma^{\prime}}$ and $\alpha_{\sigma^{\prime \prime}}$ inferred above, we find that the ratio $\frac{\phi(T)}{\phi\left(T_{0}\right)}$ is close to 0.9 in the case $\alpha_{\sigma^{\prime}}=0.033{ }^{\circ} \mathrm{C}^{-1}$ but decreases from 0.6 to 0.5 in the case $\alpha_{\sigma^{\prime}}$ $=0.06{ }^{\circ} \mathrm{C}^{-1}$ with increasing temperature (Fig. A1). We use the latter temperature-dependence to estimate the temperature-corrected laboratory MPA in our study. If the coefficient $\alpha_{\sigma^{\prime \prime}}=0.0213^{\circ} \mathrm{C}^{-1}$, inferred from data presented by Ghorbani et al. (2018), were to be used instead of $\alpha_{\sigma^{\prime \prime}}=0.0282^{\circ} \mathrm{C}^{-1}$ inferred from data presented by Vinegar \& Waxman (1984), it would lead to excessive correction (temperature-corrected laboratory MPA would become smaller than field MPA).

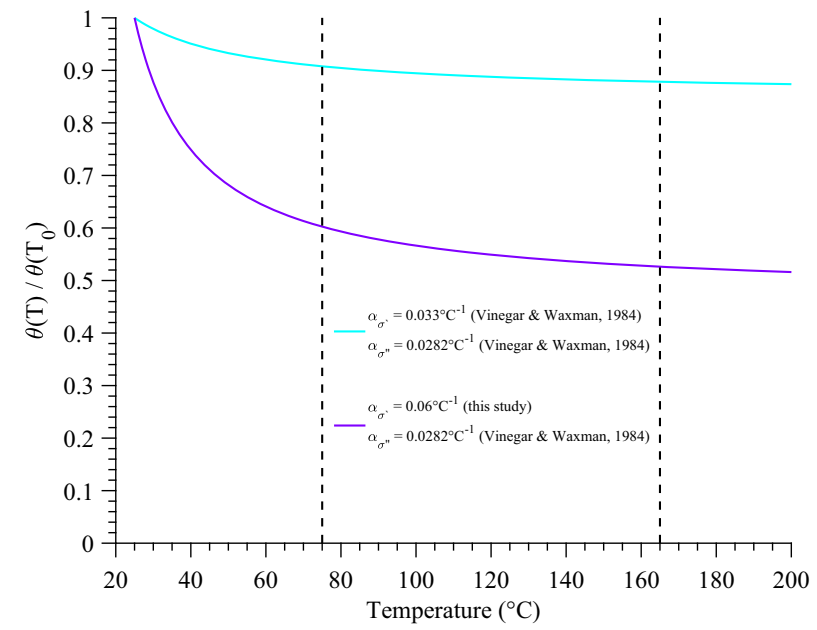

Figure B1. Decrease of phase angle with temperature increasing from 25 to $200^{\circ} \mathrm{C}$, based on eq. (B2). The correction coefficient $\alpha_{\sigma^{\prime \prime}}=0.0282^{\circ} \mathrm{C}^{-1}$ is used for the quadrature conductivity and two different correction coefficients are used for the in-phase conductivity: $\alpha_{\sigma^{\prime}}=0.06^{\circ} \mathrm{C}^{-1}$ (magenta line, based on temperature-dependence observed on samples from this area) and $\alpha_{\sigma^{\prime}}=$ $0.033^{\circ} \mathrm{C}^{-1}$ (cyan line, based on samples from Vinegar \& Waxman 1984 ). The range of temperatures relevant for samples in borehole KH1 is within the two black broken lines. 